NBER WORKING PAPER SERIES

\title{
IMPROVING EDUCATIONAL OUTCOMES IN DEVELOPING COUNTRIES: LESSONS FROM RIGOROUS IMPACT EVALUATIONS
}

\author{
Alejandro J. Ganimian \\ Richard J. Murnane \\ Working Paper 20284 \\ http://www.nber.org/papers/w20284
NATIONAL BUREAU OF ECONOMIC RESEARCH
1050 Massachusetts Avenue
Cambridge, MA 02138
July 2014

A version of this paper with fewer footnotes is forthcoming in the Review of Educational Research. An earlier version of this paper was published as NBER Working Paper No. 20284. The authors gratefully acknowledge comments from Mariana Alfonso, Manuel Álvarez Trongé, Felipe Barrera-Osorio, Diether Beuermann, Barbara Bruns, Julián Cristia, David Deming, Ariel Fiszbein, Juliana Guaqueta, Heather Hill, Eduardo Levy Yeyati, Michael Lisman, Juan Llach, Mariano Narodowski, Hugo Ñopo, Joao Batista Oliveira, Jeffrey Puryear, Axel Rivas, Alonso Sánchez, Ismael Sanz, Norbert Schady, Adela Soliz, Laura Trucco, Emiliana Vegas, and Eduardo Vélez Bustillo on earlier drafts of this paper. The authors acknowledge support for research assistance from the President's Office, Harvard University. The views expressed herein are those of the authors and do not necessarily reflect the views of the National Bureau of Economic Research. The authors acknowledge support for research assistance from the President's Office, Harvard University.

NBER working papers are circulated for discussion and comment purposes. They have not been peerreviewed or been subject to the review by the NBER Board of Directors that accompanies official NBER publications.

(C) 2014 by Alejandro J. Ganimian and Richard J. Murnane. All rights reserved. Short sections of text, not to exceed two paragraphs, may be quoted without explicit permission provided that full credit, including $(\subset)$ notice, is given to the source. 
Improving Educational Outcomes in Developing Countries: Lessons from Rigorous Impact Evaluations

Alejandro J. Ganimian and Richard J. Murnane

NBER Working Paper No. 20284

July 2014, Revised February 2016

JEL No. I21,I24,I25,I32

\begin{abstract}
This paper reviews and interprets the evidence from 223 rigorous impact evaluations of educational initiatives conducted in 56 low- and middle-income countries. We consider for inclusion in our review all studies in recent syntheses, which have reached seemingly conflicting conclusions about which interventions improve educational outcomes. We group interventions based on their theory of action. We derive four lessons from the studies we review. First, reducing the costs of going to school and expanding schooling options increase attendance and attainment, but do not consistently increase student achievement. Second, providing information about school quality, developmentally appropriate parenting practices, and the economic returns to schooling affects the actions of parents and the achievement of children and adolescents. Third, more or better resources improve student achievement only if they result in changes in children's daily experiences at school. Finally, well-designed incentives increase teacher effort and student achievement from very low levels, but low-skilled teachers need specific guidance to reach minimally acceptable levels of instruction.
\end{abstract}

\author{
Alejandro J. Ganimian \\ Graduate School of Education \\ Harvard University \\ 6 Appian Way \\ Cambridge, MA 02138 \\ alejandro_ganimian@mail.harvard.edu \\ Richard J. Murnane \\ Graduate School of Education \\ Harvard University \\ 6 Appian Way - Gutman 469 \\ Cambridge, MA 02138 \\ and NBER \\ richard_murnane@harvard.edu
}


IMPROVING EDUCATION IN DEVELOPING COUNTRIES

\section{Improving Education in Developing Countries: \\ Lessons from Rigorous Impact Evaluations}

Over the past two decades, developing countries have become increasingly interested in adopting education policies that are backed by rigorous evidence of effectiveness. This interest in “evidence-based” policies has resulted in a growing number of impact evaluations since the turn of the century (Vivalt 2015).

In recent years, several researchers have attempted to summarize the evidence from these impact evaluations (Conn 2014; Glewwe, Hanushek, Humpage, \& Ravina 2014; Guerrero, Leon, Zapata, Sugimaru, \& Cueto 2012; Kremer, Brannen, \& Glennerster 2013; Krishnaratne, White, \& Carpenter 2013; Masino \& Niño-Zarazúa 2015; McEwan 2014). These reviews aim to make sense of the evidence for policy-makers, who lack the time (and sometimes, the specialized training) to sift through hundreds of academic papers. They aspire to identify promising interventions as well as to point out puzzles to examine in future research.

These syntheses reach seemingly conflicting conclusions about which educational interventions improve educational outcomes (Evans \& Popova 2015). The disagreements stem, in part, from differences in the substantive and methodological criteria for including studies (e.g., some focus on studies in a geographic region, others on studies with cost-effectiveness data, and others on randomized trials). Yet, even reviews with similar inclusion criteria consider different sets of studies. Moreover, the different ways in which reviews categorize interventions result in some conflicting conclusions even when they consider the same studies.

We contribute in three ways to the ongoing debate on the lessons from rigorous impact evaluations of educational interventions in developing countries. First, we consider for inclusion in our review all of the studies in reviews released in recent years. Thus, we avoid the 


\section{IMPROVING EDUCATION IN DEVELOPING COUNTRIES}

risk of reaching conclusions about the state of the evidence simply due to an incomplete coverage of existing studies.

Second, instead of categorizing interventions according to whether they look similar or have similar names, we group them based on their theory of action. This taxonomy, like all others, has limitations. However, we believe it is helpful in generating hypotheses about why similar interventions have succeeded or failed, and in identifying areas that would benefit from further research.

Finally, instead of conducting a meta-analysis, we conduct a narrative review of the evidence. We do so to bring attention to the aspects of the design and implementation of successful educational interventions that are not easily captured in meta-analyses.

We derive four lessons from the studies we review:

1. Reducing the costs of going to school and expanding schooling options increase attendance and attainment, but do not consistently increase student achievement;

2. Providing information about school quality, developmentally appropriate parenting practices, and the economic returns to schooling affects the actions of parents and the achievement of children and adolescents;

3. More or better resources improve student achievement only if they result in changes in children's daily experiences at school;

4. Well-designed incentives increase teacher effort and student achievement from very low levels, but low-skilled teachers need specific guidance to reach minimally acceptable levels of instruction.

This paper is structured as follows. Section 2 presents our initial criteria for including studies in our review, our strategy for finding studies, our rationale for excluding some studies 
IMPROVING EDUCATION IN DEVELOPING COUNTRIES

upon closer scrutiny, our classification of the interventions that we discuss, and our standards for reporting the effects of these interventions. Section 3 discusses the results from our review. Section 4 reviews key lessons, identifies the limitations of existing evidence, and proposes some areas for policy experimentation and impact evaluations.

\section{Method}

\section{Inclusion Criteria}

We review evaluations of educational interventions in pre-primary, primary, and secondary schools that took place in low- or middle-income countries from 2000 to $2015{ }^{1}$

Outcomes. We review studies that include at least one of the following education-related outcomes: enrollment, attendance, repetition, dropout, retention, or measures of student achievement or cognitive skills.

For a subset of studies for which information on cost-effectiveness is available, we summarize the evidence. In doing so, we report the effect of interventions on student participation, student achievement, or teacher attendance for each 100 U.S. dollars (USD). (Student participation is defined as the school-level average of attendance among enrolled students - typically, based on unannounced visits). To ensure cost-effectiveness estimates are consistent across studies, we rely on the calculations of the Abdul Latif Jameel Poverty Action Lab (J-PAL), which use the methodology described by Dhaliwal, Duflo, Glennerster, \& Tulloch $(2012)^{2}$

\footnotetext{
${ }^{1}$ These classifications were developed by the World Bank and can be accessed at: http://bit.ly/1lgFrYy. Appendix A includes a full list of our inclusion criteria and exceptions: http://bit.ly/1mRJCkx.

${ }^{2}$ These estimates can be accessed at: http://bit.ly/1g7L74b (student participation), http://bit.ly/1KZNKGW (student learning), and http://bit.ly/1Mel4I1 (teacher attendance).
} 


\section{IMPROVING EDUCATION IN DEVELOPING COUNTRIES}

Interventions. We include studies of educational interventions, such as offering computer-assisted learning or altering incentives for teachers. We also include studies of health interventions, such as providing deworming drugs and iron supplements, that include at least one of the educational outcomes mentioned above.

Methods. We only include studies that take advantage of exogenous variation in the receipt of the intervention, either by randomly assigning individuals to a treatment or by exploiting quasi-random variation in treatment assignment from natural experiments. Included studies based on natural experiments use differences-in-differences, regression discontinuities, and/or instrumental variables to estimate the causal impacts of interventions. We do not consider studies that attempt to estimate counterfactual outcomes either by employing matching methods or fixed effects for individuals in pre-post comparisons.

\section{Literature Search}

We searched for studies in English in peer-reviewed journals, working paper series, and academic conferences. We conducted the final search that we describe below from January to September 2015. Figure 1 offers an overview of the search and review process. $^{3}$

Citation tracking. We consulted eight reviews of impact evaluations of educational interventions in developing countries and tracked the citations. These included meta-analyses, narrative, and vote-counting reviews. ${ }^{4}$ This search produced 253 studies, of which 119 met our inclusion criteria.

Working papers. We surveyed the education publications on 16 websites from research centers, professional associations, development banks, think tanks, and development economics

\footnotetext{
${ }^{3}$ Appendix B includes a list of all studies included in this review: http://bit.ly/1JH3jGi.

${ }^{4}$ Appendix C offers a list of the reviews: http://bit.ly/1mRJCkx.
} 
IMPROVING EDUCATION IN DEVELOPING COUNTRIES

conferences. Including this "grey” literature was crucial because this is a rapidly evolving field and we wanted to limit the influence of publication bias. ${ }^{5}$ This search produced 1,390 additional studies, of which 96 met our inclusion criteria.

Academic journals. We searched for academic articles in 18 journals in education, economics, and public policy. ${ }^{6}$ This search produced 10 additional studies, of which 8 met our inclusion criteria.

\section{Additional Exclusions}

In addition to excluding studies that did not meet our initial inclusion criteria, we exclude some studies for other reasons. We leave out studies that do not focus on a specific intervention, policy change, or treatment. We leave out three evaluations that only estimate the effect of a bundle of different interventions because it is not possible to determine the contributions of specific interventions to the reported effect.

We also exclude some studies due to methodological considerations. We leave out studies without balancing checks between treatment and control groups at baseline, as well as studies with imbalance between experimental groups at baseline.

Finally, we also exclude four studies that we could not access during our literature search. As noted in Figure 1, applying all of these criteria yields 223 unique studies that we include in our review.

Due to space considerations, we cannot discuss the findings of all studies that satisfied our inclusion criteria. So, after reviewing the evidence pertaining to studies with the same theory of action aimed at addressing the same problem, we describe one that illustrated well the

\footnotetext{
${ }^{5}$ Appendix D lists the organizations whose websites we examined: http://bit.ly/1mRJCkx.

${ }^{6}$ Appendix E provides the list of journals: http://bit.ly/1mRJCkx.
} 


\section{IMPROVING EDUCATION IN DEVELOPING COUNTRIES}

evidence from the relevant group of studies. In cases in which the results are sensitive to a particular detail (e.g., the design of incentive plans to increase teachers' effort levels), we explain this pattern. This version of the paper includes in footnotes all studies that support the argument illustrated by the evidence from each study that we describe in the paper. This version also includes in footnotes all studies that introduce minor caveats to our summary of the evidence.

\section{Classification Criteria}

The authors of reviews of impact evaluations typically develop their own categories to group what they consider to be similar interventions. Authors of meta-analyses fit categoryspecific meta-regression models, and determine the average treatment effect of each category. The assumption in these analyses is that if the authors have enough evaluations of interventions that are similar enough, they can determine whether a category of interventions works.

In this paper, we use a different approach. We group studies according to how they are trying to solve a specific problem. As shown in Figure 2, we start with the aim school systems seek to achieve: getting children to enroll in school and learn. Then, we categorize interventions according to whether they are trying to do this by increasing demand for education (left side) or by improving the supply of education (right side).

Next, we develop sub-categories of demand and supply interventions. Some interventions aim to increase demand for education by: (a) reducing the costs of attending school; (b) preparing children to learn at school; (c) making schooling pay; and/or (d) improving access to better schools. Other interventions try to improve the supply of education by: (a) increasing the quantity or quality of resources; (b) addressing students’ individual learning needs; (c) increasing teacher and/or principal effort; and/or (d) tackling teachers’ capacity. 


\section{IMPROVING EDUCATION IN DEVELOPING COUNTRIES}

Finally, we list strategies employed to increase demand and improve supply. These strategies are not exhaustive; they simply group the educational interventions that have been evaluated thus far. Admittedly, this categorization is based on our own interpretation of the (often explicit, but sometimes implicit) theory of action underlying each of the interventions in the impact evaluations we review. We believe, however, that our categories provide an intuitive way to organize the interventions. Moreover, these categories are less consequential than those used in meta-analyses. The reason is that instead of using the categories to estimate the average effect of groups of similar interventions, we discuss individual interventions in some detail. If we chose our categories differently, where we discuss each intervention would change, but what we write about each intervention would not change.

\section{Reporting Effects}

We report the effect of educational interventions using the metrics employed by the authors of the impact evaluations. We do this for two reasons. First, using the original scales in reporting the effects of programs on disparate educational outcomes facilitates communication. Second, many studies do not include the necessary information to calculate effect sizes. Instead of excluding these studies, we try to contextualize the effects of all interventions by reporting the target population and impact time frame.

We focus on the average effects of interventions, rather than on subgroup effects, due to space considerations. We only make two exceptions: we report heterogeneous effects when they provide insights about the mechanism through which the intervention is making a difference or when heterogeneous effects are the sole focus of a study. We also focus on the effects of the offer (not the receipt) of interventions because they are the more relevant parameters for policymakers, who cannot control whether individuals take up the interventions for which they are 
IMPROVING EDUCATION IN DEVELOPING COUNTRIES

eligible. Whenever this is not possible, we clarify that we are reporting the effect of receiving the intervention.

\section{Results}

\section{Building Demand for Education}

Reducing the costs of attending school. One reason children and youths may not go to school is because the cost of doing so is too high. Several interventions have tried to address this problem by: (a) reducing the direct costs of schooling; (b) reducing the costs of complements to schooling; or (c) improving school amenities.

Reducing the direct costs of schooling. The traditional way in which school systems have reduced the direct costs of schooling has been to lower or eliminate user fees. These policies have increased enrollments in primary school. Barrera-Osorio, Linden, \& Urquiola (2007) evaluated the impact of an initiative in Bogotá, Colombia that reduced school fees for low-income families in 2004. They found that the program increased the enrollment of primary school children in the poorest households by $3 \%$ and the enrollment of children in the nextpoorest households by $6 \% .^{7}$

In countries where many children are not attending school, the sudden influx of students from low-income families prompted by user fee eliminations can put a strain on the public school system. Lucas \& Mbiti (2012) examined the impact of fee elimination in primary education in Kenya in 2003. The policy increased the number of students who completed

\footnotetext{
${ }^{7}$ This evidence is consistent with that of Gajigo (2014) in the Gambia. As Borkum (2012) showed in South Africa, the magnitude of the impact of fee elimination policies depends on the baseline enrollment and socio-economic status of potential beneficiaries. In Shaanxi, China a tuition relief program for low-income junior high school students in rural areas increased enrollment in senior high schools by 9.7 percentage points (Liu et al. 2013). Yet, this type of program has not always improved student achievement (Chen et al. 2013; Yi et al. 2012).
} 


\section{IMPROVING EDUCATION IN DEVELOPING COUNTRIES}

primary school. However, it led to a small reduction in the achievement of students on track to graduate. It also prompted parents from wealthier families to switch their children to private schools (see also Bold, Kimenyi, Mwabu, \& Sandefur 2011).

Another popular approach to reducing the direct costs of schooling is to build new schools closer to the homes of potential students. These initiatives have increased enrollments by reducing the time children spend commuting to school. Duflo (2001) evaluated the impact of a large primary school construction program in Indonesia between 1974 and 1978. Each primary school constructed per 1,000 children led to an average increase of .12 to .19 years of schooling (depending on how the effect was estimated). ${ }^{8}$

Two types of school construction have also led to improvements in student achievement: village-based schools and pre-schools. Burde \& Linden (2013) found that the construction of “village-based” schools (i.e., schools serving only children in the neighboring area) in Ghor, Afghanistan in 2007 not only increased girls’ enrollment in schools by 52 percentage points; it also improved their math and language test scores by .65 standard deviations (SDs). In fact, for each USD 100, the program yielded a 2.11 SD effect on student achievement. Similarly, Berlinski, Galiani, \& Gertler (2009) found that construction of pre-primary schools in Argentina between 1993 and 1999 improved the third grade Spanish and math test scores of beneficiaries by .23 SDs. $^{9}$

\footnotetext{
${ }^{8}$ Similarly, Mocan \& Cannonier (2012) found that the construction and rehabilitation of basic education facilities in Sierra Leone in 2001 increased the educational attainment of women by .5 years of schooling. Conversely, Liu, Zhang, Luo, Rozelle, \& Loyalka (2010) found that the consolidation of primary schools with low enrollment in Shaanxi and Ningxia, China in 2001 did not harm student achievement.

${ }^{9}$ This evidence is consistent with that of Martinez, Naudeau, \& Pereira (2013), who found that the construction of community-based pre-schools in Gaza, Mozambique in 2008 improved the cognitive, fine motor, and socio-
} 


\section{IMPROVING EDUCATION IN DEVELOPING COUNTRIES}

A promising alternative for reducing commuting costs is providing students with a means of transportation to school. Muralidharan \& Prakash (2013) found that a program in Bihar, India that offered girls in secondary school bicycles to travel to school increased their enrollment by $30 \%$ and reduced the gender gap in enrollment by $40 \%$. In fact, the initiative was more costeffective in increasing school attendance than cash transfers for families (reviewed below).

Reducing the costs of complements. Another strategy to increase school enrollments is to lower the costs of complements to schooling. Such interventions have had positive impacts on students who take advantage of these cost reductions. Evans, Kremer, \& Ngatia (2009) found that primary school students who received free uniforms in Busia, Kenya in 2002 were 44\% more likely to attend school and they performed .25 SDs better on math, English, and Kiswahili tests after one year. For each USD 100, the program yielded a .71 years increase in student participation. Unfortunately, the authors do not report the effect of the offer of free uniforms on student achievement.

Complementary inputs are more likely to have a positive impact when there are few or no transaction costs to obtaining them. Ma et al. (2014) found that offering free eyeglasses to fourth and fifth graders at school in Gansu, China in 2012 improved their math test scores by .11 SDs.

emotional skills of beneficiaries, and improved their school readiness. Bouguen, Filmer, Macours, \& Naudeau (2014), however, found that construction of pre-schools did not yield these benefits in Cambodia, where families had enrolled pre-primary school aged students in primary when there was no available pre-school and the introduction of pre-schools prohibited this practice. 


\section{IMPROVING EDUCATION IN DEVELOPING COUNTRIES}

Yet, offering vouchers for free eyeglasses that families could redeem at the local county hospital had no such effect. ${ }^{10}$

Covering the costs of complements to schooling can be budget neutral in terms of the cost per student if the number of students per classroom is allowed to increase. Kremer, Moulin, \& Namunyu (2003) assessed the impact of an initiative in Busia and Teso, Kenya in 1995 that covered the costs of textbooks, classroom constructions, and school uniforms. The program led to a sharp reduction in dropout rates and an influx of new students into participating schools. ${ }^{11}$ The authors found no evidence that the higher student-teacher ratios reduced the achievement of already-enrolled students.

Improving school amenities. Yet another approach to increasing enrollments is to improve amenities in schools.

Perhaps the most common initiative is to provide free meals at school. Although some initiatives aim specifically at improving the nutrition of children (we discuss those below), others are conceived as "food-for-education" programs. These initiatives have a mixed tracked record. For example, Vermeersch \& Kremer (2004) found that free breakfasts in pre-schools in Busia and Teso, Kenya in 2000 increased student attendance by 30\%. The program improved students' scores on oral and written tests only in schools with experienced teachers. ${ }^{12}$ Afridi (2011),

\footnotetext{
${ }^{10}$ This evidence is consistent with that of Glewwe, Park, \& Zhao (2014), who evaluated a similar initiative in Gansu, China in 2004 and found that only 70\% of the students with poor vision who were offered eyeglasses accepted them. Doing so required scheduling an additional meeting with an optometrist.

${ }^{11}$ A similar intervention in Manicaland, Zimbabwe also reduced dropout rates (Hallfors et al. 2011).

${ }^{12}$ Similarly, Kazianga, De Walque, \& Alderman (2012) compared the effectiveness of free lunches and take-home rations in the Sahel region of Burkina Faso in 2006. After a year, both programs increased the enrollment of primary school students by 4 to 5 percentage points and improved math test scores.
} 


\section{IMPROVING EDUCATION IN DEVELOPING COUNTRIES}

however, found that a school meals program in Madhya Pradesh, India in 2003 had no impact on the attendance and enrollment of primary school students on average. ${ }^{13}$

Another way of improving school amenities is to build school latrines. Adukia (2014) found that a large school-latrine-construction initiative in India in 2003 increased enrollment in grades 1 through 5 by $12 \%$ and that of students in grades 6 through 8 by $8 \%$. At younger ages, girls and boys benefited from either unisex or sex-specific latrine constructions; at older ages, however, girls only benefited from sex-specific latrines. In contrast, Oster \& Thornton (2011) found that providing free sanitary products to girls in grades 7 and 8 in Chitwan, Nepal had no impact on their absenteeism rates. Together, these studies suggest that providing safe, private spaces for pubescent girls is a more effective way of curbing menstruation-related absences than improving sanitation technology. ${ }^{14}$

Building schools with “girl-friendly” facilities consistently increases enrollments, but it does not always result in improved student achievement. Kazianga, Levy, Linden, \& Sloan (2013) found that constructing primary schools equipped with sex-specific latrines, canteens, take-home rations, and textbooks in Burkina Faso in 2005 increased enrollments by 19 percentage points and math and French test scores by .41 SDs after two years and a half. Yet, Dumitrescu, Levy, Orfield, \& Sloan (2011) found that a similar initiative in Niger in 2008 increased enrollment by 4.3 percentage points, but had no impact on student attendance or French and math test scores.

\footnotetext{
${ }^{13}$ Similarly, Buttenheim, Alderman, \& Friedman (2011) found little evidence that a school feeding program in Lao PDR in 2006 improved enrollment or student achievement.

${ }^{14}$ Freeman et al. (2012) found that improving water quality, sanitation, and hygiene in schools in Nyanza, Kenya did not reduce student absence. Yet, some areas in this study were affected by post-election violence.
} 
IMPROVING EDUCATION IN DEVELOPING COUNTRIES

Preparing children to learn at school. Another reason why children may not go to school is that they are not well prepared (e.g., cognitively or physically). Some interventions have sought to: (a) provide children with vital medications; (b) improve their nutrition; or (c) improve parental practices.

Providing children with vital medications. Offering children medications against preventable diseases is a cost-effective way to increase enrollment and attendance; however, its impact on student achievement is mixed. Some interventions have provided deworming drugs. For example, Miguel \& Kremer (2004) found that a mass treatment of intestinal helminths (e.g., hookworm, roundworm, whipworm, and schistosomiasis) in primary schools in Busia, Kenya in 1998 reduced student absenteeism by one quarter. By reducing the prevalence of the helminths, the program also reduced the absenteeism of untreated children in treated schools, as well as that of children in neighboring schools. The program was highly cost-effective: for each USD 100, it yielded 13.9 additional years of student participation. However, the program did not improve the English, math, and science test scores of third through eighth graders. Yet, Grigorenko et al. (2006) assessed a similar initiative in Bagamoyo and Kibaha, Tanzania in 1997 and found that the offer of access to deworming drugs improved the performance of children in grades 2 to 5 on a battery of cognitive tests, with impacts ranging from .18 to .36 SDs.

Other interventions have provided treatment for malaria, which is a major cause of child morbidity in many low-income countries. These initiatives have not improved student achievement. For example, Brooker \& Halliday (2015) found that an intermittent screening and treatment program for malaria for students in grades 1 through 5 in Kwale and Msambweni, 


\section{IMPROVING EDUCATION IN DEVELOPING COUNTRIES}

Kenya in 2010 had no impact on literacy or numeracy. ${ }^{15}$ Effects on cognitive skills do not emerge later in life either. Jukes et al. (2006) tracked the beneficiaries of a malaria prevention treatment in Farafenni, the Gambia after 14 to 16 years and found no effects on memory, attention, reasoning, knowledge, or language, even though the intervention resulted in an increase of .52 years of schooling. ${ }^{16}$

Improving nutrition. There are essentially two approaches to improving the nutrition of students from low-income families: providing them with nutrients that they often lack in their diet or offering them free school meals.

A number of interventions have provided children with basic nutrients. Iron supplements have generally succeeded in improving students’ cognitive skills. For example, Baumgartner et al. (2012) compared the effects of providing iron and fatty acid supplements to primary school

\footnotetext{
${ }^{15}$ This evidence is consistent with that of Fernando, De Silva, Carter, Mendis, \& Wickremasinghe (2006), who found that a similar program in Moneragala, Sri Lanka in 1999 had no impact on the language and reading achievement of students in grades 1 through 5. Only Clarke et al. (2008) found that beneficiaries of a malaria treatment in primary and secondary school in Bondo, Kenya in 2005 performed better on assessments of sustained attention and counting sounds. Yet, beneficiaries did no better in inattentive or hyperactive-compulsive behavior or on a social science exam.

${ }^{16}$ These findings are consistent with those of Cutler, Fung, Kremer, Singhal, \& Vogl (2007), who found that a malaria eradication program in India in the 1950s did not lead to gains in literacy or primary school completion. An approach that has received comparatively less attention in this body of literature is to offer incentives to schools to provide children with vital medications. Sylvia et al. (2013) found that this approach benefited disadvantaged students in China, but at the expense of their healthier peers.
} 


\section{IMPROVING EDUCATION IN DEVELOPING COUNTRIES}

children in KwaZulu-Natal, South Africa in 2009 and found that only iron supplements improved the number of words children could recall. ${ }^{17}$

Other nutrients have increased school participation, but not student achievement. For example, Hamazaki et al. (2008) found that fatty acids provision in Lampung, Indonesia made fourth through sixth graders .4 times more likely to attend school. ${ }^{18}$ Yet, Osendarp et al. (2007) found that providing micronutrients (iron, zinc, folate, and vitamins), fatty acids, or both had no impact on the verbal skills, memory, general intelligence, or attention of primary school students in Jakarta, Indonesia in 2003.

Combining deworming drugs with micronutrients has improved school participation, but it has not always improved children’s cognitive skills. Bobonis, Miguel, \& Puri-Sharma (2006) found that delivering iron supplements and deworming drugs to pre-school students in Delhi, India in 2001 reduced student absenteeism by one fifth. For each USD 100, it increased student participation by 2.7 years. Jinabhai et al. (2001) assessed the impact of providing deworming drugs, iron, and/or vitamin A to primary school children in KwaZulu-Natal, South Africa in 1995. They found that deworming drugs, by themselves and jointly with vitamin A and/or iron

\footnotetext{
${ }^{17}$ Similarly, Manger et al. (2008) found that micronutrient fortification in Ubon Ratchathani, Thailand in 2002 increased the number of words that primary school children could recall. Luo et al. (2012) also found that iron tablets improved the math achievement of fourth graders in Shaanxi, China in 2008. The only exception has been Rico et al. (2006), who found that providing iron, zinc, or both had no impact on cognitive performance among first graders exposed to lead in Torreón, Mexico in 2001. As Kleiman-Weiner et al. (2013) showed in Gansu, China the mode of delivery of iron supplements matters. Chewable vitamins improved the math achievement of fourth graders, but eggs (a popular alternative) did not.

${ }^{18}$ Similarly, Mahawithanage et al. (2007) found that vitamin A provision improved the attendance of primary school children in Moneragala, Sri Lanka in 2001.
} 


\section{IMPROVING EDUCATION IN DEVELOPING COUNTRIES}

fortification, had impacts of similar magnitude on auditory and intellectual functions, memory, and math achievement. ${ }^{19}$ Yet, Solon et al. (2003) found that combining micronutrients with deworming drugs had no impact on the verbal, non-verbal, and quantitative abilities of primary school children in Batangas, the Philippines in 1998.

The evidence on the effects of free school meals on student achievement varies widely. Part of that variation stems from the type of food the intervention provides. Whaley et al. (2003) compared three school feeding programs for first graders in Embu, Kenya in 1998: a vegetable stew that was complemented with meat, another one that was served with milk, and a third one with additional oil equivalent to the energy provided in the meat and milk versions. Children who were offered the stew with meat outperformed all other groups in their ability to organize perceptual detail, reason by analogy, and draw comparisons. Children assigned to the meat- and oil-based stews outperformed their control group peers in arithmetic skills. ${ }^{20}$

Improving parenting practices. Many different initiatives have tried to help parents support their children. Interventions that improve parent-child interactions have had positive impacts on childhood cognitive outcomes, by themselves and when combined with other

\footnotetext{
${ }^{19}$ There is some evidence that these interventions may positively impact achievement in the long term. Maluccio et al. (2009) tracked individuals who were exposed to the delivery of protein-rich energy in Guatemala from 1969 to 1977 a quarter century later. They found that beneficiaries performed .25 SDs better on nonverbal cognitive assessments.

${ }^{20}$ How school meals are delivered also matters, but it is not clear how. Adelman, Alderman, Gilligan, \& Lehrer (2008) compared an on-site school-feeding program to take-home rations offered to children of primary school age in Pader and Lira, Uganda in 2005 and found they affected different outcomes. The caloric content of school meals has not been found to make a difference in educational outcomes. McEwan (2013) compared meal rations with different calories in Chile in 2001 and found that additional calories had no impact on enrollment, attendance, school entrance age, repetition, or language and math achievement.
} 


\section{IMPROVING EDUCATION IN DEVELOPING COUNTRIES}

treatments. $^{21}$ Attanasio et al. (2014) found that weekly home visits from community members to show mothers activities they could do with their children aged 12 to 24 months improved children’s cognitive skills by .26 SDs and their receptive language by .22 SDs.

The educational and cognitive effects of these interventions persist over time. For example, Walker, Chang, Powell, \& Grantham-McGregor (2005) assessed the long-term effects of a similar home visitation program that targeted the mothers of children aged 9 to 24 months in Kingston, Jamaica from 1986 to 1989. They found that students assigned to the intervention had higher IQ, better vocabulary, and better verbal and reading skills 17 to 18 years after the intervention. $^{22}$

Helping parents to support their children’s learning is more difficult once children are older. Banerji, Berry, \& Shotland (2014) compared adult literacy classes for mothers of children aged 5 to 8, training for mothers to enhance their children's learning at home, and a combination

${ }^{21}$ These interventions have also improved school participation. Tieffenberg, Wood, Alonso, Tossutti, \& Vicente (2000) found that a program in Buenos Aires, Argentina that trained children with asthma and epilepsy and their parents to manage the chronic illnesses reduced student absenteeism. Similarly, Rocha \& Soares (2010) found that professional health care teams assigned to a group of families in Brazil in 1995 increased the enrollment of children ages 10 to 17 in school almost every year for eight years.

${ }^{22}$ Similarly, Kagitcibasi, Sunar, \& Bekman (2001) compared two types of early enrichment activities for children ages 3 and 5 in Istanbul, Turkey: a child-focused, center-based version; and a mother-centered, home-based version. They found that both versions improved children's cognitive skills at the end of the four years of the program. Yet, children assigned to the mother-centered version had higher educational attainment, primary school grades, and vocabulary scores seven years after the end of the intervention. The positive effects on children assigned to the child-centered version had dissipated by then. Rosero \& Oosterbeek (2011) compared the effects of home visits and childcare centers on children from low-income families in Ecuador in 2006. They found that home visits improved children’s cognitive skills and reduced mothers' labor force participation; childcare centers had the opposite effect. 
IMPROVING EDUCATION IN DEVELOPING COUNTRIES

of both treatments in Bihar and Rajasthan, India. These programs improved math scores only modestly—.04, .05, and .07 SDs, respectively_and only the third treatment had an effect (.05 SDs) on language scores.

Most efforts to improve parental practices that have been rigorously evaluated require considerable commitment from parents over a sustained period of time. An approach that has received relatively little attention in developing countries is nudging parents to adopt better practices via text messages. Mo et al. (2014) found that weekly text messages to parents in Ningxia, China improved students' math achievement when accompanied by monthly quiz questions to assess parents' understanding of the messages. Text messages by themselves had no such effect.

Making schooling pay. Low-income families may not send their children to school because the cost of foregoing the alternative (e.g., employing children at home or in the labor market) seems too high. Some interventions have tried to: (a) compensate families for foregone opportunities; (b) inform them of the long-term benefits of schooling; or (c) offer incentives to students.

Compensating families for foregone opportunities. The most common approach to compensating low-income parents for the opportunity cost of schooling is to offer them cash if they enroll their children in school. Many versions of these "conditional cash transfers" or CCTs (sometimes labeled as scholarships) have been rigorously evaluated in a wide variety of contexts.

Nearly every CCT that has been evaluated has increased student enrollment. ${ }^{23}$ Yet, the magnitude of this impact has depended on the characteristics of the beneficiaries. CCTs have

\footnotetext{
${ }^{23}$ There is some evidence that CCTs are more effective at improving some educational outcomes than alternative supply-side interventions. Glewwe \& Olinto (2004) found that CCTs in Honduras in 2000 increased enrollment
} 


\section{IMPROVING EDUCATION IN DEVELOPING COUNTRIES}

had especially large impacts on the enrollment of students transitioning between levels of schooling (e.g., from primary to lower secondary school) (Schultz 2004), ${ }^{24}$ children of age to be in grades with especially low enrollment rates (Maluccio \& Flores 2005), ${ }^{25}$ and students from the poorest families (Galiani \& McEwan 2013). ${ }^{26}$

The magnitude of the impact of cash transfers has also depended on several features of program design. Treatment exposure makes a difference. Behrman, Parker, \& Todd (2009) found that children who were exposed for a longer time to CCTs in Mexico from 1997 to 2003 experienced greater impacts on educational attainment. ${ }^{27}$

rates by 1 to 2 percentage points, school attendance (conditional on enrollment) by about .8 days per month, annual promotion rates by 2 to 4 percentage points, and reduced the dropout rate by 2 to 3 percentage points. Grants to parent-teacher associations had no impact on these outcomes.

${ }^{24}$ In fact, for each USD 100, the program yielded .03 additional years of student participation. There have been multiple impact evaluations of the CCT in Mexico that find positive effects (Attanasio, Meghir, \& Santiago 2012;

De Janvry, Finan, Sadoulet, \& Vakis 2006; Dubois \& Rubio-Codina 2012; Skoufias 2001; Skoufias, Parker, Behrman, \& Pessino 2001; Todd \& Wolpin 2003). CCTs have increased educational attainment in many other contexts (Levy \& Ohls 2007; Mo et al. 2013; Ravallion \& Wodon 2000; Rogers, Chanturidze, \& MacAuslan 2013; Sparrow 2007).

${ }^{25}$ These findings are consistent with those of Behrman, Sengupta, \& Todd (2005) in Mexico, of Attanasio, Fitzsimmons, \& Gomez (2005) in Colombia, and of Maluccio, Murphy, \& Regalia (2010) in Nicaragua.

${ }^{26}$ These findings are very similar to those of Oosterbeek, Ponce, \& Schady (2008) in Ecuador. Other characteristics of beneficiaries, however, seem to be less important. For example, Behrman, Gallardo-García, Parker, Todd, \& Vélez-Grajales (2012) found that the Mexican CCT, typically assessed in rural areas, also had positive impacts on enrollment and attainment in urban areas.

${ }^{27}$ See also Behrman, Parker, \& Todd (2011). However, Fernald, Gertler, \& Neufeld (2009) found that children with longer program exposure did not perform better on a language assessment. Perova \& Vakis (2012) found suggestive evidence that CCTs in Peru in 2006 benefited children who had been exposed to the program for a longer period of 


\section{IMPROVING EDUCATION IN DEVELOPING COUNTRIES}

The schooling outcomes on which cash transfers are made conditional also matter. For example, Barrera-Osorio, Bertrand, Linden, \& Perez-Calle (2011) compared the effects of three CCTs in Bogotá, Colombia in 2005. One version transferred money to low-income parents if their child was enrolled in school and attended $80 \%$ of the days of each month. The second made a third of the transfer conditional on the child enrolling in the next grade. The third provided a smaller monthly transfer, but also provided a lump sum transfer when the child graduated from high school. All versions increased school attendance, but the second one also increased grade promotion by 4 percentage points, and the third increased tertiary enrollment by 48.9 percentage points.

One fear about CCTs is that they might reduce the school enrollment of non-eligible siblings of recipients. The limited available evidence indicates that this rarely occurs. For example, Ferreira, Filmer, \& Schady (2009) found that CCTs in Cambodia in which eligibility varied substantially among siblings made recipients 20 percentage points more likely to be enrolled in school without affecting the enrollment of ineligible siblings. ${ }^{28}$

Families' perceptions of the conditionality of cash transfers matters. For example, Schady \& Araujo (2008) found that CCTs in Ecuador in 2003 improved enrollment in primary

time. These findings are consistent with those of Chitolina, Foguel, \& Menezes-Filho (2013) in Brazil and those of Dammert (2009) in Nicaragua.

${ }^{28}$ These findings are consistent with those of CCTs that target girls. For example, Alam, Baez, \& Del Carpio (2011) found that a CCT that targeted girls in Punjab, Pakistan in 2003 increased their enrollment in middle school by 9 percentage points at no detriment to their male siblings. CCTs targeting girls have also improved their educational outcomes in Punjab, Pakistan (Chaudhury \& Parajuli 2010) and Cambodia (Filmer \& Schady 2008). In fact, Hasan (2010) found that CCTs targeting girls in grades 6 through 8 in Punjab, Pakistan in 2003 also made boys more likely to enroll. 


\section{IMPROVING EDUCATION IN DEVELOPING COUNTRIES}

and secondary school by 3.7 percentage points even when the enrollment requirement was never enforced. ${ }^{29}$ Benhassine, Devoto, Duflo, Dupas, \& Pouliquen (2013) found that "labeled cash transfers” (i.e., not conditional on school attendance, but labeled as an education support program) in Morocco in 2008 had roughly the same impact on attendance (about 7.3 percentage points) as CCTs. ${ }^{30}$ However, conditionality may serve as a commitment device in the mediumterm. Baird, McIntosh, \& Ozler (2011) found that although “unconditional cash transfers” (UCTs) targeting adolescent girls in Malawi in 2008 reduced dropout after two years, the impact was only $43 \%$ as large as that of otherwise comparable CCTs. The authors found that the CCTs produced a .06 SD impact on English test scores for each USD $100 .^{31}$

Only one type of CCTs has improved student achievement: merit scholarships. For example, Kremer, Miguel, \& Thornton (2009) assessed a program in Busia and Teso, Kenya that awarded a scholarship for two years to girls in grade 6 with the top scores on district exams of English, geography/history, mathematics, science, and Swahili. The program improved the average test scores of girls in schools assigned to the program by .19 SDs across the five subjects. In Busia, where the program was most successful, it produced .27 additional years of

\footnotetext{
${ }^{29}$ The fact that beneficiaries thought that the conditions would be enforced, however, was crucial. Amarante, Ferrando, \& Vigorito (2011) found that CCTs in Uruguay in 2005 had no impact on school enrollment, but they noted that only $20 \%$ of households were aware of the enrollment conditionality.

${ }^{30}$ Ambler, Aycinena, \& Yang (2013), however, found that matching grants for remittances intended for, but not conditioned on education in El Salvador in 2011 did not increase student enrollment.

${ }^{31}$ Conditionality may have other benefits. Akresh, De Walque, \& Kazianga (2013) found that in Burkina Faso, CCTs were more effective than UCTs in improving the enrollment of children who were initially less likely to go to school. Bursztyn \& Coffman (2012) found that in Distrito Federal, Brazil parents preferred CCTs over UCTs when they lacked mechanisms to ensure that their children attend school.
} 


\section{IMPROVING EDUCATION IN DEVELOPING COUNTRIES}

student participation, a 1.37 SD increase in test scores, and 50 more days of teacher attendance for each USD $100 .^{32}$

There is mixed evidence on whether the impact of CCTs on children's developmental outcomes depends on the size of the cash transfers. Fernald, Gertler, \& Neufeld (2008) found that doubling the size of a cash transfer in Mexico in 1998 improved children's cognitive development and receptive language. ${ }^{33}$ Yet, Macours, Schady, \& Vakis (2012) compared two CCTs of different amounts in Nicaragua in 2005 and found that children in families assigned to receive the larger transfers did not have better development outcomes than those assigned to receive the smaller transfers.

Informing families of the long-term benefits of schooling. Some low-income parents do not enroll their children in school because they underestimate the economic returns to education. ${ }^{34}$ Informing low-income families about the economic returns to schooling has

\footnotetext{
${ }^{32}$ This evidence is consistent with that of Barrera-Osorio \& Filmer (forthcoming), who compared need- and meritbased scholarships in Cambodia in 2008 and found that both increased enrollment and attendance, but only the latter had an effect on math achievement and memory (by .17 SDs and .14 SDs, respectively). Conventional CCTs have been less successful in improving student achievement. For example, Filmer \& Schady (2014) found that CCTs in Cambodia in 2006 improved school enrollment and attendance, but cash recipients did no better on math and vocabulary tests. This evidence is consistent with that of Baez \& Camacho (2011) in Colombia. However, regular CCTs may impact student achievement over the long run. For example, Barham, Macours, \& Maluccio (2014) found that a CCT in Nicaragua improved the reading, spelling, word identification, math fluency and problems, and vocabulary of boys who were 9 to 12 years old at the start of the program (in 2000) 10 years later (in 2010).

${ }^{33}$ See also Manley, Fernald, \& Gertler (2015).

${ }^{34}$ The traditional way in which governments have tried to influence the schooling decisions of these families is by raising the number of compulsory years of education. This approach has increased educational attainment. For example, Fang, Eggleston, Rizzo, Rozelle, \& Zeckhauser (2012) found that extending the number of years of
} 


\section{IMPROVING EDUCATION IN DEVELOPING COUNTRIES}

increased both attainment and achievement. For example, Jensen (2010) found that providing boys in eighth grade in the Dominican Republic in 2001 with information about the wages of adults with different levels of education resulted in an average increase of .20 to .35 more years of completed schooling. For each USD 100, the program yielded 3.1 additional years of student participation. $^{35}$

What and how information is delivered matters. Nguyen (2009) found that asking teachers to convey to parents and their children the economic returns to schooling in Madagascar in 2007 improved student attendance by 3.5 percentage points and test scores in math, French, and Malagasy by .20 SDs. For each USD 100, this program yielded a 118.34 SD effect on test scores and 20.7 years of student participation. However, asking a "role model” of poor background to share his/her educational experience and achievements had an impact on poor children's test scores, but asking a role model of rich background had no effect.

Providing information about economic returns has had unintended consequences in some settings. Loyalka et al. (2013) found that asking teachers in Hebei and Shaanxi, China to deliver a lesson to their seventh graders about the economic returns to schooling and the availability and cost of high schools had no effect on dropout rates, math achievement, or students' plans to go to high school. However, combining this lesson with three additional lessons about China's

mandatory tuition-free education from six to nine in 1968 increased the attainment of Chinese children by .8 years of schooling. Similarly, Spohr (2003), found that the same law increased the attainment of males and females in Taiwan by .40 and .25 years of schooling, respectively. Yet, these papers cannot tease out whether the effects are caused by the part of the reform that extended compulsory schooling or by the part that made the compulsory years tuition-free.

${ }^{35}$ Similarly, Jensen (2012) found that recruiting for the business processing industry in India in 2003 increased the enrollment of girls ages 6 to 17 by 5 percentage points. 


\section{IMPROVING EDUCATION IN DEVELOPING COUNTRIES}

economy, and strategies for identifying career interests and navigating China’s education system resulted in a 2 percentage point increase in the student dropout rate and reduced math achievement by .14 SDs. The authors speculated that providing information about the relatively high wages for unskilled labor may have dissuaded students from going to high school. ${ }^{36}$

Offering incentives to students. Many students have a hard time seeing how behaving and/or doing well in school will pay off. One policy response has been to offer students incentives to perform better in school.

Interventions that reward students for obtaining a minimum score on an exam have generally not succeeded in raising student achievement. For example, Angrist \& Lavy (2009) found that offering cash to students for passing the national high school exit exam in Israel in 2000 had no effect on the average passing rates of students. Interventions that reward students for their scores (i.e., so that students’ rewards are proportional to their performance) have fared better. For example, Sharma (2010) found that offering cash to eighth graders in Nepal in 2009 based on their average grades in nine compulsory subjects improved their average aggregate scores by .09 SDs. $^{37}$

The design of incentives matters. For example, Li, Han, Zhang, \& Rozelle (2014) found that providing cash rewards to the parents of primary school students in Beijing, China that made

\footnotetext{
${ }^{36}$ In a related intervention, Dinkelman \& Martínez (2013) found that providing low-income eighth graders with information about how to finance higher education in Chile in 2009 reduced student absenteeism in primary school by 8 to 10 percentage points, and increased enrollment in college preparatory secondary schools by 6 percentage points. However, providing this information to parents had no effects.

${ }^{37}$ Different rewards may appeal to different types of students. For example, Berry (2014) found that in Gurgaon, India non-cash incentives were more effective for low-achieving students, whereas cash incentives were more effective for high performers.
} 


\section{IMPROVING EDUCATION IN DEVELOPING COUNTRIES}

the greatest improvement in school grades had no impact on students' test scores. Yet, offering an additional reward to a high-achieving student for serving as a peer tutor improved math and reading test scores by .14 SDs. They also found that calling parents to explain the intervention to them (in addition to the cash incentives and peer tutoring) improved math and reading achievement by .2 SDs. ${ }^{38}$

Cash incentives for students based on measures of academic performance may elicit dysfunctional responses. Behrman, Parker, Todd, \& Wolpin (2015) found that providing Mexican high school students with cash incentives for reaching minimum scores on a math exam led between 8.4 and $14.9 \%$ of students to cheat in the first year of the experiment, and the percentage increased in each of the next two years.

Improving access to better schools. Even if parents understand the potential value of schooling, they may choose not to enroll their children if they perceive the quality of their local schools to be too low to yield benefits. To address this problem, several interventions have tried to: (a) provide families with information about the quality of available schools; or (b) expand schooling options for these families.

Providing information about school quality. Some argue that providing parents with information about the performance of schools can help them make better decisions about where to send their children to school, and demand improvements in their schools. The modest amount of evidence bearing on this hypothesis is encouraging.

\footnotetext{
38 This evidence is consistent with that of Blimpo (2014), who found that providing cash incentives for individual students in Benin in 2008 improved the average aggregate test scores in seven subjects by .29 SDs, offering the incentives to teams of students improved test scores by .27 SDs, and making teams compete for the incentives improved test scores by .34 SDs. Although the impacts of the different treatments varied, the author could not rule out the possibility that they are all equally effective.
} 


\section{IMPROVING EDUCATION IN DEVELOPING COUNTRIES}

Andrabi, Das, \& Khwaja (2009) provided parents (and schools) in Punjab, Pakistan in 2004 with a report card that displayed the test scores of their own children and the average scores of students in all schools in each village. As a result, children's test scores in English, math, and Urdu improved by an average of .11 SDs. The gain persisted for two years after the intervention. Much of this improvement was driven by a .31 SD increase in the test scores of students’ enrolled in private schools. Student test scores in public schools also improved, albeit only by .10 SDs. These findings suggest that information spurs competition among private schools and also enables parents to demand changes in public schools. ${ }^{39}$

Expanding schooling options. A number of interventions have tried to make private schools more accessible to children from low-income families. In some countries, all public

${ }^{39}$ As Mizala \& Urquiola (2013) contend, however, a school’s average test score is a poor indicator of their quality; schools with more students from low-income families may have low average scores even if they are improving the achievement of their students. Thus, they assessed whether schools that were identified as being among the top $25 \%$ within a group of schools serving students of similar socio-economic status in Chile in 2002 improved educational outcomes. They found no impact of this policy on school enrollment. Yet, this study is problematic for at least two reasons. First, unlike the one in Pakistan, it did not compare responses across educational markets with different levels of information, but rather schools within a market with the same level of information. Second, and perhaps more importantly, schools that rank in the top $25 \%$ also received a monetary bonus, so this study estimated the effect of information and bonuses rather than the effect of information alone. Other studies on this subject are also problematic. For example, Camargo, Camelo, Firpo, \& Ponczek (2011) found that a reform in 2006 that disclosed the average scores of the college entrance exam of high schools with more than 10 students improved the performance of private schools by .2 to .6 SDs, but did not affect the performance of public schools. However, it has been widely documented that schools with too few students have noisier average test scores (Kane \& Staiger 2001, 2002), which is probably why the minimum threshold of students was instituted in the first place. This makes the effects difficult to interpret. 


\section{IMPROVING EDUCATION IN DEVELOPING COUNTRIES}

school students are eligible to receive vouchers. These are known as "universal” voucher systems. ${ }^{40}$ In other countries, only low-income families are eligible. These are known as “targeted” voucher systems.

In some contexts, targeted vouchers have had positive short- and medium-term impacts. For example, Angrist, Bettinger, Bloom, King, \& Kremer (2002) found that a voucher program in Colombia in 1991 had no impact on enrollment in secondary school, but it increased the attainment of students assigned to vouchers by .10 years of schooling and their test scores on math, reading, and writing by .20 SDs after three years. Angrist, Bettinger, \& Kremer (2006) found that the voucher offer increased the probability that youths from low-income families graduated from secondary school by 6 to 7 percentage points, and it improved their performance on college entrance exams. ${ }^{41}$

\footnotetext{
${ }^{40}$ Hsieh \& Urquiola (2006) found that a universal voucher system in Chile, in place since 1981, which provided all families with children with the same valued vouchers had no effect on test scores, repetition rates, or years of schooling. This system increased school segregation by income, with low-income students concentrated in different schools than those serving students from higher-income families. Contreras (2001) found that students who were more likely to attend private, voucher-accepting schools in Chile because they had more such schools in their neighborhood performed better on standardized scores. However, school density is likely to be influenced by the intensity of families’ interest in school quality.

${ }^{41}$ Bettinger, Kremer, \& Saavedra (2010) report that, among voucher applicants to vocational schools, students who were offered a voucher were less likely to attend an academic secondary school than those not offered a voucher and consequently had lower-achieving peers. Yet, the students offered vouchers had better educational outcomes. This suggests that improved peer groups was not the only mechanism through which vouchers resulted in improved academic performance.
} 


\section{IMPROVING EDUCATION IN DEVELOPING COUNTRIES}

These findings are encouraging. ${ }^{42}$ However, it is possible that the initiative influenced the achievement of students other than those who used vouchers to switch to private schools. One plausible mechanism is that public school students who switched to private schools may have reduced peer group quality both in the public schools they left and in the private schools to which they moved.

Muralidharan \& Sundararaman (2015) designed an experiment in Andhra Pradesh, India in 2008 to address both of these concerns. First, they invited students attending public schools in a number of villages to apply for vouchers to attend private schools (we call these students "voucher applicants"). Then, they randomly selected some of those villages to be those in which some applicants would be awarded vouchers for private schooling (we call these villages “voucher villages”). In voucher villages, a random subset of voucher applicants was awarded vouchers. This two-stage lottery allowed the authors to examine the impact of the vouchers on lottery winners as well as the potential spillover effects of the program on non-applicants in public schools and on students who were already in private schools at the start of the experiment.

Muralidharan and Sundararaman assessed the skills of students in participating villages two and four years after the start of the experiment. They found that voucher winners in voucher villages performed about the same in Telugu and math as voucher applicants in non-voucher

\footnotetext{
${ }^{42}$ These findings are also consistent with those of other studies that sought to increase student choice. For example, Lavy (2010) found that a program that ended forced busing and allowed students greater choice among secondary schools in Tel Aviv, Israel in 1994 significantly reduced dropout rates and increased the cognitive achievement of high school students after six years. As Wong, Luo, Zhang, \& Rozelle (2013) found in Henan, China, the quality of the schools where the vouchers can be redeemed is crucial in understanding why some vouchers have impacts and others do not. The authors found that vouchers for pre-school attendance improved attendance by 20 percentage points, but had no impact on school readiness. They attributed these results to the poor quality of pre-schools.
} 


\section{IMPROVING EDUCATION IN DEVELOPING COUNTRIES}

villages. However, after four years, students in the first group performed .12 SDs better in English and .55 SDs better in Hindi (a subject taught only at private schools) than students in the second group. Importantly, this improvement did not occur at the expense of non-applicants or lottery losers in public schools, or of non-applicants who already attended private schools. Since the cost of schooling in the private schools was considerably less than the cost of public schooling (because teacher salaries were much lower), the authors contend that this voucher system was a cost-efficient way to improve the schooling of children from low-income families.

An alternative approach to vouchers is to offer per-student subsidies to private schools that serve low-income students without charging tuition or fees. In Pakistan, the only developing country where these initiatives have been rigorously evaluated, they have had promising results. For example, Barrera-Osorio et al. (2013) found that per-student subsidies to private primary schools in Sindh, Pakistan in 2009 increased enrollment by 30 percentage points and language and math test scores by .67 SDs. ${ }^{43}$

However, the success of per-student subsidies may depend on the level of capacity to set up and maintain private schools. Alderman, Kim, \& Orazem (2003) compared two programs in Balochistan, Pakistan that invited local associations in urban and rural areas to set up their own private schools and paid them per girl enrolled. The program in urban areas increased girls’ enrollment, but the one in rural areas did not. The authors speculated that this was because urban

\footnotetext{
${ }^{43}$ Similarly, Barrera-Osorio \& Raju (forthcoming) found that accountability-based per-student subsidies in Punjab, Pakistan increased enrollment by 59 percent. An approach that has received far less attention in developing countries is the creation of excellent schools for disadvantaged students. Loyalka, Wei, \& Zhong (2015) found that building two "elite” secondary schools in Ningxia, China in 2003 and 2006 increased college attendance by 8.6 to 14.4 percentage points, depending on how the effect was estimated.
} 


\section{IMPROVING EDUCATION IN DEVELOPING COUNTRIES}

areas had more out-of-school children not served by public schools, a better local pool of teachers, and more adults with the knowledge needed to manage private schools successfully.

\section{Improving the Supply of Education}

Increasing the quantity or quality of resources. Children from low-income families typically live in homes and attend schools with few educational resources. Many interventions have: (a) increased resources at school; (b) increased resources at students' homes; or (c) expanded instructional time.

Increasing resources at school. A number of interventions have provided schools with teaching inputs, such as textbooks, libraries, or flipcharts. These inputs have not improved student achievement for two reasons: sometimes, they are not used; and other times, they are used but they do not markedly alter children’s daily experiences at school.

The case of textbooks illustrates the first reason. Glewwe, Kremer, \& Moulin (2009) found that providing free official textbooks in English, math, and science to students in grades 3 through 8 in Busia and Teso, Kenya in 1995 had no impact on English, math, or science test scores on average. The authors explain that most students could not read the books because they were written in English, most students’ third language. ${ }^{44}$

The case of flipcharts illustrates the second reason additional resources did not produce greater student achievement. Glewwe, Kremer, Moulin, \& Zitzewitz (2004) found that providing flipcharts to primary schools in Busia and Teso, Kenya in 1998 (charts for science, health, and math; a teacher's guide for science; and a map for geography) had no impact on eighth grade test

\footnotetext{
${ }^{44}$ Similarly, Sabarwal, Evans, \& Marshak (2013) found that providing free textbooks to government, governmentassisted, and community primary schools in Sierra Leone in 2008 had no impact on enrollment, attendance, or achievement. Yet, these results are explained by the actions of school principals who, fearing a shortage of textbooks in the future, stored the textbooks instead of giving them to students.
} 


\section{IMPROVING EDUCATION IN DEVELOPING COUNTRIES}

scores. This occurred even though 98\% of teachers knew that their school had received flipcharts, 91\% said they had used them, and 92\% reported that they were useful. A likely explanation is that teachers lacked the knowledge of how to use these resources to improve instruction and thereby to change students’ experiences in school. ${ }^{45}$

This problem also emerges in recent initiatives that provide schools with desktop computers or laptops. Barrera-Osorio \& Linden (2009) found that installing refurbished computers in public schools and encouraging teachers to use them to teach reading in Colombia in 2002 had no impact on students' Spanish or math test scores. ${ }^{46}$ The reason was that teachers of core subjects did not integrate them into their classroom instruction. Cristia, Ibarrarán, Cueto, Santiago, \& Severín (2012) found the same pattern of results from an initiative that provided free laptops with 39 educational applications and 200 e-books to students in rural regions of Peru.

An alternative to providing schools with specific inputs, which they may not know how to use, is to offer funds that schools may use to purchase whatever inputs they feel they need. Interestingly, however, Das et al. (2013) found that school grants in Andhra Pradesh, India and Zambia had a positive impact on student outcomes when they were unexpected, but had no impact when they were expected. In India, school grants that were announced late in the school year improved language and math scores by .08 and .09 SDs, respectively, but had no impact in the following year, when they were expected. In Zambia, well-publicized grants in 2001 had no

\footnotetext{
${ }^{45}$ The pressure to use resources may take away from regular instruction. Borkum, He, \& Linden (2013) found that equipping schools with libraries and having librarians provide reading-focused activities in Bangalore, India in 2007 had no impact on students' scores on a language test. In fact, a version of the program in which schools did not house the libraries, but had librarians visit schools reduced test scores.

${ }^{46}$ This evidence is consistent with that of Angrist \& Lavy (2002), who found that the installation of computers in primary and lower secondary schools in Israel in 1994 did not improve test scores.
} 


\section{IMPROVING EDUCATION IN DEVELOPING COUNTRIES}

impact on student achievement, but discretionary district-level funding, which is harder to predict, improved English and math test scores by .10 SDs. A clue to the explanation for this puzzling pattern is that in both settings parents responded to grants that were anticipated by reducing their own expenditures on education. Thus, these increases in public funds did not markedly increase the total resources devoted to children's education. ${ }^{47}$

Increasing resources at home. Many children in developing countries lack basic educational resources at home. To stimulate their learning at school, several interventions have provided children with resources they can take home-typically, desktop computers or laptops. These initiatives have not improved student achievement. For example, Malamud \& PopEleches (2011) found that low-income students aged 7 to 19 in Romania who were offered vouchers to purchase personal computers in 2004 performed worse in math, English, and

\footnotetext{
${ }^{47}$ Bjorkman (2007) studied how funds for schools in different districts of Uganda affected student achievement. She took advantage of variation across districts in newspaper penetration, and consequently, in the potential impact of a newspaper campaign aimed at preventing substitution of public funds for private funds. She found that students in districts exposed to the information campaign (and hence to the grant program) scored .40 SDs higher on a test that covered math, English, science, and social studies. However, before the intervention, student achievement in districts with high newspaper penetration may not have increased at the same rate as in districts with low newspaper penetration. An alternative to school grants that has received less attention is the introduction of school-based savings accounts. Karlan \& Linden (2013) compared two variations of this approach in Busoga, Uganda in 2009. The first version set up savings accounts for students at their school and gave them back the money in cash they had deposited at the end of each trimester, in time for purchasing school supplies. The second version gave them back the money in vouchers, so that their parents could only use it to buy school supplies. They found the first version improved students' test scores in grammar and reading, but only when it was combined with a program that informed parents about how they could support their children's education. The second version had no effect on any educational outcomes.
} 


\section{IMPROVING EDUCATION IN DEVELOPING COUNTRIES}

Romanian by .25, .33, and .30 SDs, respectively, although they increased their computer skills and performed better on a test of intelligence. The apparent explanation is that students offered a voucher reported spending more time playing computer games and less time reading and doing homework. $^{48}$

Expanding instructional time. In many low-income countries, the average student attends schools for only half the day (about four hours). In response to concerns that this may not provide enough time for children to master critical skills, many developing countries have lengthened their school days. Typically, they have accompanied this with an increase in material resources. Studies of these combined initiatives typically find that they produced small improvements in student achievement.

To our knowledge, there is only one study of the consequences of simply increasing instructional time. ${ }^{49}$ Orkin (2013) found that lengthening the school day from four to six hours

${ }^{48}$ Similarly, Beuermann, Cristia, Cruz-Aguayo, Cueto, \& Malamud (2013) found that providing students in Lima, Peru with laptops in 2011 did not improve their performance on general personal computer and Internet skills, even thought it did improve their performance by .88 SDs on an assessment of proficiency in handling the speciallydesigned laptop they were given. This policy also made children less likely to read books, stories, or magazines. There was little evidence of spillover effects on general skills, even though friends of students assigned to receive a laptop performed better on the assessment measuring how to handle that special laptop.

${ }^{49}$ Bellei (2009) evaluated the full school day program in Chile in 1996 and found that every 10\% increase in the number of hours per day improved the Spanish and math test scores of tenth graders by .02 and .03 SDs, respectively. Yet, this reform was accompanied by a one-time investment in school facilities (to construct or renew classrooms, cafeteria, bathrooms, etc.) and a permanent increase in the amount of the public per-student subsidy. Similarly, Lavy (2012) found that every 10\% expansion in the hours devoted to English, math, and science per week in Israel in 2004 improved the test scores of fifth graders in these subjects by .03 SDs. Yet, this increase was accompanied by a change in funding formulas that altered school budgets. Agüero \& Beleche (2013) found that 


\section{IMPROVING EDUCATION IN DEVELOPING COUNTRIES}

in Ethiopia in 2005 resulted in first through third graders being 2.17 to 2.74 times more likely to be proficient in math and 3.51 to 4.18 times more likely to be proficient in writing, but had no impact on their writing proficiency.

Addressing students’ individual learning needs. Teachers in many low- and middleincome countries struggle to meet the individual learning needs of heterogeneous student populations. Several interventions have tried to: (a) help teachers personalize instruction; (b) provide additional help to struggling students; or (c) use technology to facilitate students learning at their own pace.

Helping teachers personalize instruction. A common strategy to enable teachers to cater to students' individual needs is to reduce the number of students per classroom. A number of countries have done this, often by imposing a maximum class size rule. Evaluating the impact of these rules, however, has been difficult because responses by principals, teachers, and parents create differences between the characteristics of students in small and larger classes. ${ }^{50}$ These responses render invalid the common strategy of estimating the impact of class size by

every 10 additional days in school in Mexico in 2005-2007 improved the math achievement of students in grades 4 and 5 by .04 and .05 SDs, respectively. Yet, their estimation relies on arbitrary variation in testing dates, which does not allow teachers to plan to use their time differently.

${ }^{50}$ For example, Urquiola \& Verhoogen (2009) showed that a maximum class size rule in Chile led to two important responses: high-income parents of children who were assigned to a large class moved them to another school, and principals of private schools manipulated admissions to avoid triggering class size reductions that would necessitate hiring additional teachers. 


\section{IMPROVING EDUCATION IN DEVELOPING COUNTRIES}

comparing the performances of students in classrooms just below and just above the maximum class size. ${ }^{51}$

The best available evidence is that class size reductions in developing countries are effective only when initial class sizes are very large, the reductions radically change the number of students in the classroom, and students are tracked by their initial achievement. Duflo, Dupas, \& Kremer (2011) compared two interventions in Western Province, Kenya in 2005. One offered funds to primary schools to split their first grade class into two sections and hire a teacher on a contractual basis to teach the extra section. The second did the same, but also required schools to assign students to classes based on their prior achievement. On average, class size reductions lowered the average number of students per class from 91 to 44 students in non-tracking schools and from 89 to 42 students in tracking schools. After 18 months, math and literacy test scores were .14 SDs higher in tracking than in non-tracking schools. In fact, the combination of smaller classes and tracking raised the scores of students of all initial achievement levels. This intervention yielded a 34.56 SD effect for each USD 100 when the authors accounted for the baseline characteristics of the treatment and control groups.

Tracking students across schools has had different consequences than tracking them to different classes within schools. In some developing countries, students are assigned to secondary schools based on their performance at the end of primary school. For example, PopEleches \& Urquiola (2013) found that a rule in Romania that allows students to choose their secondary school based on their performance on a nationwide exam improved the performance

\footnotetext{
${ }^{51}$ Two papers that meet our search criteria used this strategy (Asadullah 2005; Urquiola 2006). As Chin (2005) showed in the case of India, an alternative is to compare students in different cohorts and states. Yet, in the reform she evaluated, due to misallocation of teachers, class sizes were ultimately not reduced.
} 


\section{IMPROVING EDUCATION IN DEVELOPING COUNTRIES}

of students right above a pre-determined cutoff by .02 to .10 SDs. ${ }^{52}$ This policy, however, also had unintended consequences. Teachers with higher certification credentials gravitated to betterranked schools. Parents reduced their effort (e.g., helping students with their homework) when their children were admitted to a better school. And finally, children who were admitted to a better school by a small margin perceived themselves as weak and marginalized. ${ }^{53}$

Another approach to helping teachers personalize instruction is to give them feedback on their students’ achievement. Existing evidence suggests that simply providing teachers with diagnostics is not effective. For example, Muralidharan \& Sundararaman (2010) found that providing teachers in grades 1 through 5 in Andhra Pradesh, India in 2005 with the results of diagnostic tests increased teacher effort, but did not improve the achievement of their students.

Feedback for teachers only improves student achievement when it is accompanied by initiatives that build teachers’ capacity or make their jobs more manageable. For example, Duflo, Berry, Mukerji, \& Shotland (2015) found that simply replacing high stakes exams with more frequent evaluation of students by teachers had no impact on the achievement of students in grades 1 through 8 in Haryana, India in 2012. Yet, assessing students'skills at the start of the

52 This evidence is consistent with that of De Hoop (2010), who found that students assigned to better-ranked schools in Malawi increased progression to the second year of secondary school by 50\%, without a reduction in student achievement. Similarly, Jackson (2010) found that students assigned to better-ranked schools in Trinidad and Tobago performed better on secondary school exit exams. As Jackson (2013) showed, much of the benefit derived from these schools is from interacting with high-achieving peers. Yet, the dimension along which students are tracked across schools matters. Jackson (2012) found that, on average, students assigned to single-sex schools in Trinidad and Tobago perform no better on their tenth grade exams.

${ }^{53}$ A related, but different policy that aims to help teachers personalize instruction is grade retention. To our knowledge, there is only one rigorous evaluation of this type of policy. Chen, Liu, Zhang, Shi, \& Rozelle (2010) found that a grade retention policy in Shaanxi, China had no impact on Chinese language scores. 


\section{IMPROVING EDUCATION IN DEVELOPING COUNTRIES}

year and setting aside a portion of the school day to group and teach students according to their ability level improved the achievement of students in grades 1 through 5 in oral and written Hindi by .15 and .14 SDs, respectively. ${ }^{54}$

Providing additional help to students. Another way to address students' needs is to offer additional support to low-achieving students. Banerjee, Cole, Duflo, \& Linden (2007) assessed the effect of hiring young female high school graduates in Mumbai, India in 2001 to take lowachieving students in grades 3 and 4 out of class for two hours during the school day and provide them with remedial instruction using a highly structured curriculum. The program increased math and language test scores by .14 SDs after the first year, and by .28 SDs after the second year. For every USD 100, the program yielded a 3.05 SD effect after the first year. ${ }^{55}$

Some interventions provide students with a mix of academic and non-academic support. These programs have been difficult to implement. For example, Cabezas, Cuesta, \& Gallego (2011) assessed a three-month program in Gran Santiago and Bío Bío, Chile in which fourth graders met 15 times with college volunteers who read them age-appropriate texts. On average,

\footnotetext{
${ }^{54}$ Similarly, Piper \& Korda (2011) found that a program with four components in Liberia in 2008 had a positive impact on seven positive literacy outcomes ranging from .39 to 1.23 SDs. The components included assessing the reading proficiency of students in grades 2 and 3 in Liberia in 2008, training teachers on how to assess student performance, providing them with pedagogical support and books, and providing parents and the community with student report cards.

55 This evidence is consistent with that of Lavy \& Schlosser (2005), who found that a short-term remedial education program that provided additional instruction to underperforming secondary school students in Israel in 1999 raised the school mean matriculation rate. Duc \& Baulch (2012) used the enrollment of a child's peers in extra classes in Vietnam to estimate the effect of that child's attending extra classes. They found that the number of hours students spent in extra classes had no impact on mathematics and vocabulary assessments. Yet, the enrollment of peers in extra classes is likely to directly influence achievement.
} 


\section{IMPROVING EDUCATION IN DEVELOPING COUNTRIES}

the program did not improve the cognitive skills of the students. One reason may be that volunteer turnover was high in Gran Santiago. ${ }^{56}$

Using technology to facilitate students learning at their own pace. Instead of asking teachers to cater to students’ individual needs, some initiatives have experimented with computer-assisted learning (CAL). These are (typically, game-based) computer programs that include exercises focusing on basic skills required by the official curricula.

These programs have generally improved student achievement. For example, Banerjee et al. (2007) assessed a program that provided children in grade 4 with two hours of shared computer time per week (one hour during class time and one hour either before or after school) to interact with game-based CAL software focused on the basic competencies of the official math curriculum in Gujarat, India in 2002. The program improved math achievement by .35 SDs after one year and .47 SDs after two years. For every USD 100, the program yielded a 1.54 SD effect after two years. ${ }^{57}$

These programs are most effective when they are a complement to, rather than a substitute for conventional classroom instruction. Linden (2008) compared two versions of the CAL program discussed above in Gujarat, India in 2004: an out-of-school time version, which

\footnotetext{
${ }^{56}$ Similarly, Huan et al. (2014) found that providing school counseling to seventh and eighth graders in Shaanxi, China in 2013 reduced dropout rates by 25\% after six months, but it had no impact on dropout rates after a year. In part, this seemed to be because students found counseling more important and interesting after six months than at the end of the year.

${ }^{57}$ The benefits of some programs persist over time. For example, Lai et al. (2013) found that a game-based CAL program for math held outside of regular school hours in Shaanxi, China in 2011 improved the math test scores of third and fifth graders by .12 SDs after six months. Mo et al. (2014) then found that after a year and a half of being implemented, the program improved the math scores of third and fifth graders by .25 and .26 SDs, respectively.
} 


\section{IMPROVING EDUCATION IN DEVELOPING COUNTRIES}

took place either before or after school, and a pull-out program, which took place for two hours during school. The first version improved students’ math test scores by .28 SDs. The second version, however, reduced achievement by .57 SDs from what it would have been in the absence of the program. ${ }^{58}$

In other settings, these programs have been found effective when implemented during time allotted to computer class. For example, Mo et al. (2014) assessed use of game-based CAL software for math in Shaanxi, China in 2011. The initiative entailed two 40-minute instructorsupervised sessions per week, in which two students shared one computer. Participation was compulsory and instructors took attendance regularly. The program improved the math test scores of third and fifth graders by .16 SDs.

These programs can be combined with provision of laptops, which by themselves have had no impact on student achievement. Mo et al. (2013) assessed a program in Beijing, China in 2011 that provided third grade migrant students with free laptops on which three tutoring programs were installed: a commercial, game-based, math CAL program, a similar program for Chinese, and a math CAL program devised by the research team jointly with experts. The researchers trained students and their parents to interact with the computer, so that parents could

\footnotetext{
58 This evidence is consistent with that of Lai, Luo, Zhang, Huang, \& Rozelle (forthcoming), who found that a game-based CAL program in Beijing, China in 2010 that included two 40-minute sessions per week during lunch break or after school improved the math test scores of third graders by .14 SDs. Similarly, Lai et al. (2012) found that a game-based CAL program for Mandarin held outside of regular school hours in Qinghai, China in 2011 improved the test scores of third graders in Mandarin and math by .14 to .20 SDs and .22 to .23 SDs, respectively. Yang et al. (2013) found that girls and boys benefited equally from three programs in Beijing, Shaanxi, and Qinghai, China. Yet, when Huang et al. (2014) considered two more programs, they found some evidence that boys benefited more from CAL programs for Chinese than girls.
} 


\section{IMPROVING EDUCATION IN DEVELOPING COUNTRIES}

supervise children at home. The program improved students’ computer skills by .33 SDs and math test scores by .17 SDs. ${ }^{59}$

Increasing teacher and/or principal effort. In some developing countries, teachers are often absent from school; when they are in school, they are not always teaching or preparing classes; and when they are teaching, they devote too much time to non-instructional tasks. In response to these problems, a number of interventions have: (a) increased the role of parents and communities in school management; (b) offered incentives to teachers and principals; and (c) hired teachers on fixed-term, renewable contracts.

\section{Increasing the role of parents and communities in school management. Many} interventions have tried to involve parents and community members in monitoring teacher and principal performance and managing schools. The rationale behind most of these initiatives is twofold. First, parents and communities have a clear incentive to make schools work. Second, parents and communities may also understand the needs of their schools better than national or regional authorities.

The least intrusive of these interventions provide information to communities about opportunities to get involved. Evaluations indicate that more information does not consistently translate into greater involvement. For example, Banerjee, Banerji, Duflo, Glennerster, \& Khemani (2010) found that providing information to communities in Uttar Pradesh, India in 2005 about the existence of village education councils, their membership, resources, and roles

\footnotetext{
${ }^{59}$ CAL programs have also been useful complements to programs that donate computers to schools. Carrillo, Onofa, \& Ponce (2011) assessed a program in Guayaquil, Ecuador in 2007 that donated four computers to primary schools, installed on those computers a CAL program for math and language, trained teachers and principals on computing skills and the software, and engaged parents at various stages. They found that the program improved the math achievement of third through fifth graders by .38 SDs after two years, but had no impact on language skills.
} 


\section{IMPROVING EDUCATION IN DEVELOPING COUNTRIES}

did not increase the involvement of parents, local authorities, and teachers in public schools, and did not reduce student and teacher absenteeism. Combining this information with training for community members about how to administer a testing tool for children had similar results. ${ }^{60}$

Similar interventions have affected intermediate outcomes, but have had only small and isolated effects on student achievement. Pandey, Goyal, \& Sundararaman (2009) assessed the impact of providing information to communities on their oversight roles in schools and education services in Karnataka, Madhya Pradesh, and Uttar Pradesh, India in 2006. The intervention increased teacher attendance by 7 percentage points in Uttar Pradesh, but on average it had no effect in Madhya Pradesh. It had no effect on teacher activity (i.e., whether the teacher was teaching) in Uttar Pradesh, but it increased teacher activity in Madhya Pradesh by 9 percentage points. The intervention produced small improvements (from .03 to .08 SDs) only on some subtests of math and reading for some grades, and did not do so consistently across sites. ${ }^{61}$

A more intrusive approach is to provide schools with monetary grants that community members play a role in administering. The effect of these interventions has depended on the preexisting level of community capacity. For example, Beasley \& Huillery (2015) found that

\footnotetext{
${ }^{60}$ As Barr, Mugisha, Serneels, \& Zeitlin (2012) have shown in Uganda, one reason why more information does not always lead to more participation is because of coordination problems. They found that an intervention that trained and supported members of management committees of primary schools to administer a report card with information on school performance had no effect on student or teacher absenteeism, or on student test scores. However, a similar intervention in which the members of these committees were engaged in a dialogue to design their own monitoring instrument reduced student and teacher absenteeism and improved test scores.

${ }^{61}$ Similarly, Reinikka \& Svensson (2011) found that in 1997, when the government of Uganda began publishing information about the amounts of funds for education transferred to districts in national newspapers, enrollment in primary school increased. However, they found small effects on test scores.
} 


\section{IMPROVING EDUCATION IN DEVELOPING COUNTRIES}

providing monetary grants to primary schools in Tahoua and Zinder, Niger in 2007 increased parental participation and student enrollment in the early grades. However, teacher absenteeism increased, and there was no impact on student achievement. The authors concluded that parents lacked the authority and capacity to use the additional funds to improve school quality. ${ }^{62}$

School grants seem to be most effective when they are combined with interventions that build the capacity of communities. For example, Pradhan et al. (2014) compared the impact of seven variations of a school grants program in Indonesia in 2007: grants by themselves; grants combined with training on planning, budgeting, and management; grants combined with guidelines for school committee elections and roles; grants combined with joint planning meetings between school committees and village councils; and combinations of the last three variations. They found that grants combined with joint planning meetings improved language test scores by .17 SDs. For each USD 100, this intervention yielded a 34.62 SD effect. When the grants were also combined with guidelines for school committee elections, they improved

\footnotetext{
${ }^{62}$ This evidence is consistent with that of Gertler, Patrinos, \& Rubio-Codina (2012), who found that providing monetary grants to parent associations that they could use for infrastructure or materials for schools in Mexico in 1996 reduced grade failure by $7.4 \%$ and grade repetition by $5.5 \%$ in grades 1 to 3 . However, the program had no effects on extremely poor communities. Similarly, Blimpo \& Evans (2011) found that a program that combined school grants with school management training for principals, teachers, and community members in primary schools in the Gambia reduced student absenteeism by $21 \%$ and teacher absenteeism by $23 \%$. However, it had no impact on average math and English test scores after three years. Finally, Carneiro, Koussihouèdé, Lahire, Meghir, \& Mommaerts (2015) found that a school grants program in Senegal in 2010 had a positive effects on the oral proficiency of female third graders. Yet, the effects were driven by schools in the south of the country, which spent the funds on human resources improvements rather than school materials.
} 


\section{IMPROVING EDUCATION IN DEVELOPING COUNTRIES}

language test scores by .23 SDs. For each USD 100, this intervention yielded a 13.34 SD effect. On average, no intervention improved math achievement. ${ }^{63}$

Offering incentives to teachers and/or principals. The evidence from impact evaluations of initiatives that provide additional compensation to educators indicates that it is not the size, but the structure of compensation that matters. Even small pay increases can improve teacher effort and student achievement when made conditional on desired and attainable outcomes.

There are very few evaluations of unconditional pay increases that meet our inclusion criteria. One that does was conducted by de Ree, Muralidharan, Pradhan, \& Rogers (2015). They assessed the impact of permanently doubling the base pay of teachers in 120 randomly selected primary and junior secondary public schools in Indonesia in 2009. They found that, after two and three years, the doubling in pay led to no improvements in teacher effort or student learning outcomes. ${ }^{64}$

There are two types of conditional pay increases that have been rigorously evaluated: those that reward teachers for additional effort and those that reward them for improving the performance of their students on standardized tests. Several interventions have offered cash or

\footnotetext{
63 This evidence is consistent with that of Lassibille, Tan, Jesse, \& Nguyen (2010), who found that the implementation of tools to streamline and tighten the workflow process of all actors across the service delivery chain in Madagascar in 2005 improved school attendance and reduced repetition, but on average, did not improve student achievement on French, math, and Malagasy. The impact of the reform did not vary by teacher type (i.e., regular v. contract teachers) (Glewwe \& Maïga 2011).

${ }^{64}$ In contrast, Menezes-Filho \& Pazello (2007) found that increases in the relative salaries of public school teachers in Brazil in 1998 improved student achievement on the national exam of Portuguese, math, and science. However, as the authors discuss, their estimation relies on the assumption that unobserved differences in proficiency across systems within municipalities are constant over time.
} 


\section{IMPROVING EDUCATION IN DEVELOPING COUNTRIES}

in-kind rewards to teachers for regular attendance. The results indicate that these programs work only when monitoring is systematic and non-discretional. Duflo, Hanna, \& Ryan (2012) assessed a program in Rajasthan, India in 2003 that provided teachers in non-formal education centers with tamper-proof cameras, required that they took pictures of themselves and their students in school every day, and offered them bonuses based on the number of days they attended. The program reduced teacher absenteeism by 21 percentage points and improved students' math and Hindi test scores by .17 SDs after 30 months. For every USD 100, the intervention yielded a 2.27 SD improvement in student achievement and 45 days of additional teacher attendance.

Teacher incentive programs that rely on principals or parents to monitor attendance and distribute incentives have not been successful. For example, Chen, Glewwe, Kremer, \& Moulin (2001) assessed a program that provided teacher training, classroom materials, and incentives for teacher attendance to pre-schools in Busia and Teso, Kenya in 1997. Principals had to track teacher attendance and distribute the bonuses. Funds not paid as bonuses could be used for other school-related purposes. Principals typically paid the entire bonus to teachers regardless of attendance. The program had no impact on teacher attendance or students' test scores. ${ }^{65}$

Several interventions have offered teachers cash incentives for improving the performance of their students on standardized tests. Some of these programs have increased student achievement. For example, Muralidharan \& Sundararaman (2011) compared two teacher incentive programs in Andhra Pradesh, India in 2005. One provided a group bonus that was

\footnotetext{
${ }^{65}$ Similarly, de Laat, Kremer, \& Vermeersch (2008) assessed a program in Busia, Kenya in 2002 in which school committees were asked to evaluate teachers on ten dimensions (e.g., attendance and punctuality, pedagogical methods, student discipline, relations with parents, attitudes towards students) and nominate teachers for in-kind rewards (e.g., bicycles, household items, or pens). The program did not increase the average attendance of teachers.
} 


\section{IMPROVING EDUCATION IN DEVELOPING COUNTRIES}

distributed to all teachers in a school, based on the average improvement of all students in that school on tests of math and language; a second provided an individual bonus to each teacher that was based on the average improvement of his or her students on standardized tests. After one year, both programs performed equally well: the group bonus and individual bonuses improved test scores in math and Telugu by .14 and .16 SDs, respectively. Yet, after two years, the individual bonus performed better, increasing test scores by .28 SDs compared to an increase of .15 SDs for the group bonus. ${ }^{66}$

In some cases, incentive programs have elicited dysfunctional responses. For example, Glewwe, Ilias, \& Kremer (2010) assessed a program in Busia and Teso, Kenya in 1997 that offered teachers of grades 4 through 8 in-kind prizes (e.g., suits, plates, and bed linens) based on the average performance and improvement of students on government exams of multiple subjects (English, math, science/agriculture, Swahili, geography, arts/music, and business). The program improved the achievement of students on the tests linked to the incentives by .14 SDs after two years. For each USD 100, the intervention yielded a 4.54 SD improvement. Yet, it did not improve students' scores on tests of the same subjects that were not linked to the incentives. This pattern suggests that teachers focused on drilling students on the types of items included on the tests that affected bonuses and that this did not produce meaningful increases in students' skills.

\footnotetext{
66 This evidence is consistent with that of McEwan \& Santibáñez (2005), who found that teachers who were assigned to receive a bonus based on their performance on an evaluation system in Mexico in 1999 had better classroom-level test scores. Similarly, Lavy (2009) found that a program that offered individual bonuses to teachers based on the performance of their students on secondary school matriculation exams in English and math in Israel in 2000 increased test-taking rates, pass rates, and mean test scores. Lavy (2013) found that male and female teachers performed equally well and that female performance did not differ by the gender mix of the competition group.
} 


\section{IMPROVING EDUCATION IN DEVELOPING COUNTRIES}

Some of these programs include provisions to discourage dysfunctional responses, but these provisions generate their own responses. For example, Barrera-Osorio \& Raju (2015) compared three teacher incentive programs in Punjab, Pakistan in 2010: one that rewarded teachers based on their school's average gain on fifth grade assessments of math, science, and Urdu; a similar one that rewarded principals based on the same metric; and another that rewarded both teachers and principals based on this measure. To prevent schools from discouraging lowachieving students from enrolling or taking the tests, the formula used to allocate the incentives also considered gains in schools' enrollment in grades 1 to 5 and the test-taking participation rate in grade 5. After three years, the program had no impact on test scores, but it increased enrollment by $4.6 \%$ and test-taking participation rates by $3.4 \%$. These findings suggest that, when faced with incentives for multiple outcomes, some of which are difficult to attain, teachers and principals respond by trying to influence the outcomes that they can affect most easily.

Hiring teachers on fixed-term, renewable contracts. In many developing nations, it is very difficult to dismiss public school teachers for low effort or performance. This has led some countries to try to reduce class sizes by hiring additional teachers on fixed-term, renewable contracts. These "contract teachers” are often not professionally trained and are paid much lower salaries than civil service teachers.

In the short-term, these initiatives have resulted in high effort among contract teachers and higher student achievement. For example, Muralidharan \& Sundararaman (2013) found that contract teachers in primary schools in Andhra Pradesh, India in 2005 were much less likely than regular teachers to be absent from school (18\% v. 27\%). After two years, students in schools with an extra contract teacher performed .16 and .15 SDs better in assessments of math and language, respectively. 


\section{IMPROVING EDUCATION IN DEVELOPING COUNTRIES}

Yet, hiring contract teachers may also lead to some undesirable responses. For example, Duflo, Dupas, \& Kremer (2015) assessed the impact of an initiative that divided grade 1 classes in Western Province, Kenya in 2005 and hired contract teachers to teach the extra class. They found that first graders assigned to civil service teachers did not improve their achievement in math and literacy, even though the reform reduced the number of students per class from 82 to 42 on average. This was at least partly due to civil service teachers reducing their effort: after the reform, they were less likely to be found in their classes teaching. In contrast, first graders assigned to a contract teachers performed .24 SDs better in math and literacy. In fact, replacing civil servants with contract teachers both increased student achievement and lowered costs. ${ }^{67}$

In the settings where pay for performance or contract teachers have shown positive impacts, student achievement and teacher attendance were extremely low. In such contexts, well-designed incentives that reward outcomes that teachers can directly affect by increasing their effort (e.g., less absence or more "time-on-task") may produce gains that are "low hanging fruit.” However, once this low-hanging fruit has been picked, further student learning improvements may be constrained by the low skills of teachers in many developing countries. In these cases, it is necessary to build the capacity of existing teachers.

\footnotetext{
${ }^{67}$ How these reforms are taken to scale matters. Bold, Kimenyi, Mwabu, Ng'ang'a, \& Sandefur (2013) compared two ways of scaling-up a contract teacher reform in all Kenyan provinces in 2009: relying on the government or on an international non-government organization. The first version improved math and English test scores by .18 SDs. The second version had no effects on student achievement. The difference in the effectiveness of these two approaches was possibly due to the fact that hiring of contract teachers in government schools showed more evidence of nepotism and local capture, schools in the government treatment arm received fewer monitoring visits, and teachers experienced longer salary delays.
} 


\section{IMPROVING EDUCATION IN DEVELOPING COUNTRIES}

Tackling teachers’ capacity. Classifying interventions aimed at increasing teachers’ effectiveness is difficult because there are often common elements across categories. However, the following categories capture much of the variation: (a) increasing teachers' skills; (b) preparing lessons for teachers; and/or (c) encouraging students to teach each other.

Increasing teachers' skills. The traditional approach to improving teacher capacity is to provide in-service training (also called professional development). Developing countries often spend large sums of money on these programs, but few have been rigorously evaluated.

Implementing professional development programs well is difficult. For example, Yoshikawa et al. (2015) assessed a professional development program for pre-K and kindergarten teachers in Santiago, Chile in 2008, that combined workshops and in-classroom coaching on oral language and literacy development, socio-emotional development, and coordination of early childhood development with health services. The quality of implementation of the professional development varied widely. This was at least part of the reason that the initiative had no impact on child outcomes. ${ }^{68}$

Even training programs that have been implemented faithfully have not consistently improved student achievement. For example, Zhang, Lai, Pang, Yi, \& Rozelle (2013) found that

\footnotetext{
${ }^{68}$ Angrist \& Lavy (2001) found that an in-service training program that focused on pedagogical strategies to teach Hebrew language skills, math, and English in Jerusalem, Israel in 1995 improved test scores in secular schools, but not test scores of students in religious schools. The authors conclude that this was partly because the program started later in religious schools and was implemented on a smaller scale.
} 


\section{IMPROVING EDUCATION IN DEVELOPING COUNTRIES}

an intensive, three-week in-service teacher training program for English teachers in Beijing, China in 2009 had no impact on students’ scores on assessments of English. ${ }^{69}$

Not all professional development efforts have been ineffective, however. Abeberese, Kumler, \& Linden (2014) assessed a month-long reading marathon in Tarlac, the Philippines in 2009, which trained teachers to incorporate reading into their curriculum, provided reading materials appropriate for the age of their students, and encouraged children to read as many books as possible during a 31-day period. This program increased the number of books students read and improved the reading test scores of fourth graders by .13 SDs. In fact, for each USD 100, the program yielded a 1.18 SD effect. These effects persisted: after three months, students assigned to the reading marathon performed .06 SDs better in reading.

Preparing lessons for teachers. Low-income countries where teacher capacity is very low have experimented with scaffolding (i.e., providing teachers with very specific instructions about how to deliver each of a set of lessons). These programs have improved student achievement.

Lucas, McEwan, Ngware, \& Oketch (2014) assessed the impact of a program that guides teachers through a highly structured five-step process for developing children’s literacy skills, and is accompanied by resources and mentoring. This initiative improved the scores of students in grades 1 and 2 on an assessment of oral literacy in Kenya by .08 SDs and the scores of

\footnotetext{
${ }^{69}$ Similarly, Yue et al. (2012) found that a training program for "life teachers” (i.e., teachers that support students in boarding schools) in Shaanxi, China in 2007 that focused on students' health, behavior, and academic performance had no impact on students’ math achievement.
} 


\section{IMPROVING EDUCATION IN DEVELOPING COUNTRIES}

students in the same grades on assessments of written and oral literacy in Uganda by .20 and .18 SDs, respectively. It did not improve numeracy in either setting. ${ }^{70}$

In some cases, teachers are given pre-recorded or scripted lessons. For example, Naslund-Hadley, Parker, \& Hernandez-Agramonte (2014) found that a program in Cordillera, Paraguay in 2011 that integrated a 30-to-40-minute pre-recorded audio in Spanish and Guaraní into math lessons, complemented with additional resources and teacher-led activities, improved the math achievement of pre-school students by .15 SDs. ${ }^{71}$

Tailoring the scaffolding approach to students’ skill levels matters. For example, He, Linden, \& MacLeod (2008) compared two approaches for teaching English in Maharashtra, India in 2005: flashcards for teacher-led drills and a machine that let students learn at their own pace. Both approaches improved the English test scores of students in grades 1 through 5: the first one by .34 SDs and the second one by .55 SDs. Both also improved students’ math test scores: the first one by .25 SDs and the second one by .39 SDs. However, low-achieving students benefited

\footnotetext{
${ }^{70}$ Impact evaluations of similar interventions have also found that these initiatives improve student achievement in the targeted subject or skill. Githua \& Nyabwa (2008) found that “advance organizers” (i.e., analogies to illustrate concepts) for math instruction in Nakuru, Kenya improved the math achievement of third graders. Spratt, King, \& Bulat (2013) found that a program that offered structured lessons, activities, and accompanying materials for teaching early reading skills in Mali in 2009 improved the reading skills of students in grades 1 and 2, after one and two years of exposure, respectively. Van Staden (2011) found that a four-step process to teach reading, which included small-group discussions, a “word wall”, exercise of word association, an assessment of reading proficiency, and teacher-led discussions improved the reading proficiency of English language learners in Free State, South Africa.

${ }^{71}$ Similarly, Piper (2009) found that a heavily scripted program to teach reading, composed of 45 lessons, in Limpopo, Mpumalanga and North West, South Africa raised the reading achievement of first graders.
} 


\section{IMPROVING EDUCATION IN DEVELOPING COUNTRIES}

more from the teacher-directed method, whereas high-achieving students benefited more from the method that allowed them to learn at their own pace.

The setting in which these pre-prepared lessons are delivered also matters. For example, He, Linden, \& MacLeod (2009) assessed a program in Mumbai, India in 2006 to teach children aged four to five to read. The program combined storybooks, flashcards, and charts with a library with age-appropriate texts. The program was implemented in three different settings: public pre-schools, public primary schools, and pre-school classes outside of school created specifically for this program. The versions of the program in public pre-schools and primary schools produced more robust gains in students’ reading skills. In public schools, the program was most effective when it took place outside of the hours of the regular school day.

Encouraging students to teach each other. Several interventions have attempted to compensate for low teacher capacity by encouraging peer-to-peer learning. These programs have worked best in secondary school, when students are most independent of the teacher. For example, Wachanga \& Mwangi (2004) found that a five-week intervention in which secondary school chemistry students in Nakuru, Kenya performed experiments and then discussed the results with their peers improved students’ performance in chemistry. ${ }^{72}$

These programs have worked less well in lower grades, where the teacher needs to play a more active role as facilitator. For example, Berlinski \& Busso (2013) assessed the impact of an approach to teaching seventh grade geometry in Costa Rica in 2011 that required students to formulate and explain hypotheses, teachers to explain the material, and students to practice

\footnotetext{
${ }^{72}$ Similarly, Ajaja \& Eravwoke (2011) found that a six-week program that required junior secondary school students in integrated science classes in Nigeria to discuss the material, help each other, and develop projects in groups, improved their achievement in integrated science.
} 


\section{IMPROVING EDUCATION IN DEVELOPING COUNTRIES}

together. The program included a teachers’ manual and a students’ workbook with exercises. The authors evaluated four versions of the program: one that only implemented the new program, one in which the teacher had an interactive whiteboard, one in which student pairs shared a laptop for two hours per week, and one in which each student had his or her own computer. All four versions of the program resulted in lower student achievement in seventh grade geometry than in regular classes without the program or the additional materials. ${ }^{73}$

\section{Discussion}

In this concluding section, we summarize the evidence that led us to the four substantive lessons listed in the introduction to the paper. We also suggest guidelines for describing evidence from program evaluations.

Some of the lessons from the 223 recent rigorous impact evaluations we reviewed concern increasing demand for more and better education. Reducing the cost of attending school, by lowering the direct costs of schooling, reducing the costs of complements, or improving school amenities, has generally increased children's enrollment and attendance in school. Yet, more time in school has not consistently resulted into higher achievement.

Preparing children to learn at school by providing medications or improving nutrition has typically increased children’s participation in school, but it has rarely improved student achievement. Initiatives aimed at influencing parental practices have been more effective in improving the developmental and academic skills of children during their first few years of life.

\footnotetext{
${ }^{73}$ Similarly, Beuermann, Naslund-Hadley, Ruprah, \& Thompson (2013) assessed a program that aimed to teach science in third grade in Lima, Peru in 2010 in which the teacher posed a problem, provided the materials to solve it, and students had to conduct their own experiments and report their results. The program improved test scores on the physical world assessment by .18 SDs, but not scores on assessments of understanding of the human body and the environment.
} 


\section{IMPROVING EDUCATION IN DEVELOPING COUNTRIES}

Making schooling pay by compensating parents for the opportunity cost of sending their children to school has increased children's time in school. However, except for merit scholarships, it has not resulted in higher student achievement. Informing families of the long-

term benefits of schooling has increased schooling and achievement, but only when students (and their parents) see it in their own interest to stay in school and learn more. Offering incentives to students to perform better in school has improved student achievement, but in some cases it has elicited dysfunctional responses.

Improving access to better schools by providing information about school quality and expanding schooling options has improved student achievement in some settings, but not others. We need to learn more about the roles of design and contextual factors in explaining this pattern.

Our review yields some useful lessons for improving the supply of education. Increasing the quantity or quality of resources, at home or at school, has had at best modest impacts on student achievement. The same is true for initiatives that have expanded the length of the school day. One potential explanation is that these reforms have typically offered "more of the same"; they have rarely changed children’s daily experiences.

There is mounting evidence that addressing students' individual learning needs, by helping teachers personalize instruction, providing additional help to struggling students, or letting students learn at their own pace, increases student achievement. Perhaps equally important, these strategies are often most effective in increasing the skills of low-achieving students and do so without harming their high-ability peers.

Increasing teacher and/or principal effort by involving parents and communities in school management has not been effective in enhancing student outcomes-especially, in settings where pre-existing capacity is low. Offering incentives to principals and/or teachers has improved 


\section{IMPROVING EDUCATION IN DEVELOPING COUNTRIES}

student achievement. However, it has proven difficult to design incentive systems that do not elicit dysfunctional responses. Hiring teachers on fixed-term, renewable contracts has increased student achievement in the short-run, but taking this policy to scale and maintaining it over time presents many challenges.

Professional development aimed at increasing teachers’ knowledge of substance and pedagogy has not increased student achievement. Pre-prepared lessons for teachers have improved student achievement in settings of low teacher capacity. Encouraging older students to teach each other shows promise.

Finally, our review offers some guidelines for discussing the evidence. First, the details of design and implementation of educational interventions matter (Pritchett \& Sandefur 2013). A corollary of this lesson is that blanket statements about the effectiveness of particular interventions, such as vouchers or computers, are neither accurate nor helpful.

Second, the average effects of interventions typically mask considerable heterogeneity across groups. It is critical to understand the effects of an intervention for specific groups because they sometimes drive average effects and because these impacts shed light on whether an intervention will work with a different population.

Third, the consequences of any school improvement strategy are likely to depend on the circumstances in the particular setting. In settings where many children are out of school, it may make sense to focus on demand-side interventions. However, in countries where most children are going to school and learning is low, improving instruction is crucial. Similarly, in settings where teacher capacity is very low, making their job easier-e.g., by tracking students by ability or preparing lessons for teachers-may produce incremental improvements. In countries where teachers have moderate capacity but low effort, aligning the incentives of students, parents, and 


\section{IMPROVING EDUCATION IN DEVELOPING COUNTRIES}

teachers may make more sense, provided that there are mechanisms to discourage, identify, and correct dysfunctional responses.

Finally, most of what we know about these interventions concerns short-term outcomes

for students. In the United States, a number of interventions have had only short-lived impacts on test scores, but large effects on important adult outcomes (Chetty et al. 2011; Kemple \& Willner 2008; Ludwig \& Miller 2007). Examining longer-term consequences of promising interventions in developing countries is an important goal for future research. 
IMPROVING EDUCATION IN DEVELOPING COUNTRIES

\section{References}

Abeberese, A. B., Kumler, T. J., \& Linden, L. L. (2014). Improving reading skills by encouraging children to read in school: A randomized evaluation of the Sa Aklat Sisikat reading program in the Philippines. Journal of Human Resources, 49, 611-633. doi: 10.1353/jhr.2014.0020

Adelman, S., Alderman, H., Gilligan, D. O., \& Lehrer, K. (2008). The impact of alternative food for education programs on learning achievement and cognitive development in Northern Uganda. Unpublished manuscript. The World bank. Washington, DC.

Adukia, A. (2014). Sanitation and education. Unpublished manuscript. Harvard Graduate School of Education. Cambridge, MA.

Afridi, F. (2011). The impact of school meals on school participation: Evidence from rural India. Journal of Development Studies, 47, 1636-1656. doi: 10.1080/00220388.2010.514330

Agüero, J. M., \& Beleche, T. (2013). Test-mex: estimating the effects of school year length on student performance in Mexico. Journal of Development Economics, 103, 353-361. doi: 10.1016/j.jdeveco.2013.03.008

Ajaja, O. P., \& Eravwoke, O. U. (2011). Effects of cooperative learning strategy on junior secondary school students achievement in integrated science. Electronic Journal of Science Education, 14(1).

Akresh, R., De Walque, D., \& Kazianga, H. (2013). Cash transfers and child schooling: Evidence from a randomized evaluation of the role of conditionality. (World Bank Policy Research Working Paper No. 6340). The World Bank. Washington, DC. 


\section{IMPROVING EDUCATION IN DEVELOPING COUNTRIES}

Alam, A., Baez, J. E., \& Del Carpio, X. V. (2011). Does cash for school influence young women’s behavior in the longer term? Evidence from Pakistan. (Policy Research Working Paper No. 5669). The World Bank. Washington, DC.

Alderman, H., Kim, J., \& Orazem, P. F. (2003). Design, evaluation, and sustainability of private schools for the poor: The Pakistan urban and rural fellowship school experiments. Economics of Education Review, 22, 265-274. doi: 10.1016/s0272-7757(02)00051-1

Amarante, V., Ferrando, M., \& Vigorito, A. (2011). School attendance, child labor, and cash transfers: An impact evaluation of PANES. Poverty and Economic Policy Research 9th General Meeting. Siem Reap, Cambodia.

Ambler, K., Aycinena, D., \& Yang, D. (2013). Subsidizing remittances for education: A field experiment among migrants from El Salvador. Unpublished manuscript. Department of Economics, University of Michigan. Ann Arbor, MI.

Andrabi, T., Das, J., \& Khwaja, A. I. (2009). Report cards: The impact of providing school and child test scores on educational markets. (Policy Research Working Paper No. 7226). The World Bank. Washington, DC.

Angrist, J., Bettinger, E., Bloom, E., King, E., \& Kremer, M. (2002). Vouchers for private schooling in Colombia: Evidence from a randomized natural experiment. American Economic Review, 1535-1558. doi: 10.3386/w8343

Angrist, J., Bettinger, E., \& Kremer, M. (2006). Long-term educational consequences of secondary school vouchers: Evidence from administrative records in Colombia. American Economic Review, 96, 847-862. doi: 10.2307/30034075 


\section{IMPROVING EDUCATION IN DEVELOPING COUNTRIES}

Angrist, J., \& Lavy, V. (2001). Does teacher training affect pupil learning? Evidence from matched comparisons in Jerusalem public schools. Journal of Labor Economics, 19. doi: $10.1086 / 319564$

---. (2002). New evidence on classroom computers and pupil learning. The Economic Journal, 112, 735-765. doi: 10.1111/1468-0297.00068

---. (2009). The effects of high stakes high school achievement awards: Evidence from a randomized trial. American Economic Review, 1384-1414. doi: 10.1257/aer.99.4.1384

Asadullah, M. N. (2005). The effect of class size on student achievement: Evidence from Bangladesh. Applied Economics Letters, 12, 217-221. doi: $10.1080 / 1350485042000323608$

Attanasio, O., Fitzsimmons, E., \& Gomez, A. (2005). The impact of a conditional education subsidy on school enrollment in Colombia (Vol. 1). Unpublished manuscript. The Institute of Fiscal Studies, Centre for the Evaluation of Development Policies.

Attanasio, O. P., Fernández, C., Fitzsimons, E. O., Grantham-McGregor, S. M., Meghir, C., \& Rubio-Codina, M. (2014). Using the infrastructure of a conditional cash transfer program to deliver a scalable integrated early child development program in Colombia: cluster randomized controlled trial. BMJ, 349, g5785.

Attanasio, O. P., Meghir, C., \& Santiago, A. (2012). Education choices in Mexico: Using a structural model and a randomized experiment to evaluate Progresa. The Review of Economic Studies, 79, 37-66. doi: 10.1093/restud/rdr015

Baez, J. E., \& Camacho, A. (2011). Assessing the long-term effects of conditional cash transfers on human capital: Evidence from Colombia. (Policy Research Working Paper No. 5681). The World Bank. Washington, DC. 


\section{IMPROVING EDUCATION IN DEVELOPING COUNTRIES}

Baird, S., McIntosh, C., \& Ozler, B. (2011). Cash or condition? Evidence from a cash transfer experiment. The Quarterly Journal of Economics, 126, 1709-1753. doi:10.1093/qje/qjr032

Banerjee, A. V., Banerji, R., Duflo, E., Glennerster, R., \& Khemani, S. (2010). Pitfalls of participatory programs: Evidence from a randomized evaluation in education in India. American Economic Journal: Economic Policy, 2, 1-30. doi: 10.3386/w14311

Banerjee, A. V., Cole, S., Duflo, E., \& Linden, L. (2007). Remedying education: Evidence from two randomized experiments in India. Quarterly Journal of Economics, 122, 1235-1264. doi: 10.3386/w11904

Banerji, R., Berry, J., \& Shotland, M. (2014). The impact of mother literacy and participation programs on child learning: Evidence from a randomized evaluation in India. Unpublished manuscript. Abdul Latif Jameel Poverty Action Lab (J-PAL). Cambridge, MA.

Barham, T., Macours, K., \& Maluccio, J. A. (2014). Assessing long-term impacts of conditional cash transfers on children and young adults in rural Nicaragua. (Impact Evaluation Report No. 17). International Initiative for Impact Evaluation (3ie). New Delhi, India.

Barr, A., Mugisha, F., Serneels, P., \& Zeitlin, A. (2012). Information and collective action in community-based monitoring of schools: Field and lab experimental evidence from Uganda. Unpublished manuscript. University of Nottingham. Nottingham, UK.

Barrera-Osorio, F., Bertrand, M., Linden, L. L., \& Perez-Calle, F. (2011). Improving the design of conditional transfer programs: Evidence from a randomized education experiment in Colombia. American Economic Journal: Applied Economics, 3, 167-195. doi: 10.1257/app.3.2.167 


\section{IMPROVING EDUCATION IN DEVELOPING COUNTRIES}

Barrera-Osorio, F., Blakeslee, D. S., Hoover, M., Linden, L., Raju, D., \& Ryan, S. P. (2013). Leveraging the private sector to improve primary school enrolment: Evidence from a randomized controlled trial in Pakistan. Unpublished manuscript. Harvard Graduate School of Education (HGSE). Cambridge, MA.

Barrera-Osorio, F., \& Filmer, D. (forthcoming). Incentivizing schooling for learning: Evidence on the impact of alternative targeting approaches. Journal of Human Resources.

Barrera-Osorio, F., \& Linden, L. (2009). The use and misuse of computers in education:

Evidence from a randomized experiment in Colombia. (Impact Evaluation Series No. 29). The World Bank. Washington, DC.

Barrera-Osorio, F., Linden, L. L., \& Urquiola, M. (2007). The effects of user fee reductions on enrollment: Evidence from a quasi-experiment. Unpublished manuscript. Department of Economics at The University of Texas at Austin. Austin, TX.

Barrera-Osorio, F., \& Raju, D. (2015). Teacher performance pay: Experimental evidence from Pakistan. Unpublished manuscript. The World Bank. Washington, DC.

---. (forthcoming). Evaluating the impacts of public student subsidies to low-cost private schools in Pakistan. Journal of Development Studies.

Baumgartner, J., Smuts, C. M., Malan, L., Kvalsvig, J., van Stuijvenberg, M. E., Hurrell, R. F., \& Zimmermann, M. B. (2012). Effects of iron and n-3 fatty acid supplementation, alone and in combination, on cognition in school children: A randomized, double-blind, placebo-controlled intervention in South Africa. The American Journal of Clinical Nutrition, 96, 1327-1338. doi: 10.3945/ajcn.112.041004 


\section{IMPROVING EDUCATION IN DEVELOPING COUNTRIES}

Beasley, E., \& Huillery, E. (2015). Willing but unable: Short-term experimental evidence on parent empowerment and school quality. Unpublished manuscript. Sciences Po. Paris, France.

Behrman, J. R., Gallardo-García, J., Parker, S. W., Todd, P. E., \& Vélez-Grajales, V. (2012). Are conditional cash transfers effective in urban areas? Evidence from Mexico. Education Economics, 20, 233-259. doi: 10.2139/ssrn.1916083

Behrman, J. R., Parker, S. W., \& Todd, P. E. (2009). Schooling impacts of conditional cash transfers on young children: Evidence from Mexico. Economic Development and Cultural Change, 57, 439-477. doi: 10.1086/596614

Behrman, J. R., Parker, S. W., \& Todd, P. E. (2011). Do conditional cash transfers for schooling generate lasting benefits? A five-year followup of PROGRESA/Oportunidades. Journal of Human Resources, 46, 93-122. doi: 10.1353/jhr.2011.0028

Behrman, J. R., Parker, S. W., Todd, P. E., \& Wolpin, K. I. (2015). Aligning learning incentives of students and teachers: Results from a social experiment in Mexican high schools. Journal of Political Economy, 123, 325-364. doi: 10.1086/675910

Behrman, J. R., Sengupta, P., \& Todd, P. (2005). Progressing through PROGRESA: An impact assessment of a school subsidy experiment in rural Mexico. Economic Development and Cultural Change, 54, 237-275. doi: 10.1086/431263

Bellei, C. (2009). Does lengthening the school day increase students’ academic achievement? Results from a natural experiment in Chile. Economics of Education Review, 28, 629640. doi: 10.1016/j.econedurev.2009.01.008 


\section{IMPROVING EDUCATION IN DEVELOPING COUNTRIES}

Benhassine, N., Devoto, F., Duflo, E., Dupas, P., \& Pouliquen, V. (2013). Turning a shove into a nudge? A “labeled cash transfer” for education. American Economic Journal: Economic Policy, 7, 86-125.

Berlinski, S., \& Busso, M. (2013). Pedagogical change in mathematics teaching: Evidence from a randomized control trial. Unpublished manuscript. Inter-American Development Bank. Washington, DC.

Berlinski, S., Galiani, S., \& Gertler, P. (2009). The effect of pre-primary education on primary school performance. Journal of Public Economics, 93, 219-234. doi:

10.1016/j.jpubeco.2008.09.002

Berry, J. (2014). Child control in education decisions: An evaluation of targeted incentives to learn in India. Unpublished manuscript. Massachusetts Institute of Technology (MIT). Cambridge, MA.

Bettinger, E., Kremer, M., \& Saavedra, J. E. (2010). Are educational vouchers only redistributive? The Economic Journal, 120, F204-F228. doi: 10.1111/j.14680297.2010.02374.x

Beuermann, D. W., Cristia, J. P., Cruz-Aguayo, Y., Cueto, S., \& Malamud, O. (2013). Home computers and child outcomes: Short-term impacts from a randomized experiment in Peru. (NBER Working Paper No. 18818). National Bureau of Economic Research (NBER). Cambridge, MA.

Beuermann, D. W., Naslund-Hadley, E., Ruprah, I. J., \& Thompson, J. (2013). The pedagogy of science and environment: Experimental evidence from Peru. The Journal of Development Studies, 49, 719-736. doi: 10.1080/00220388.2012.754432 


\section{IMPROVING EDUCATION IN DEVELOPING COUNTRIES}

Bjorkman, M. (2007). Does money matter for student performance? Evidence from a grant program in Uganda. (Working Paper No. 326). Institute for International Economic Studies (IIES), Stockholm University. Stockholm, Sweden.

Blimpo, M. P. (2014). Team incentives for education in developing countries: A randomized field experiment in Benin. American Economic Journal: Applied Economics, 6, 90-109. doi: 10.1257/app.6.4.90

Blimpo, M. P., \& Evans, D. K. (2011). School-based management and educational outcomes: Lessons from a randomized field experiment Unpublished manuscript. Stanford, CA: Stanford University.

Bobonis, G. J., Miguel, E., \& Puri-Sharma, C. (2006). Anemia and school participation. Journal of Human Resources, 41, 692-721.

Bold, T., Kimenyi, M., Mwabu, G., Ng'ang'a, A., \& Sandefur, J. (2013). Scaling-up what works: Experimental evidence on external validity in Kenyan education. Unpublished manuscript. Center for Global Development. Washington, DC.

Bold, T., Kimenyi, M., Mwabu, G., \& Sandefur, J. (2011). Why did abolishing fees not increase public school enrollment in Kenya? Unpublished manuscript. Center for Global Development. Washington, DC.

Borkum, E. (2012). Can eliminating school fees in poor districts boost enrollment? Evidence from South Africa. Economic Development and Cultural Change, 60, 359-398. doi: $10.1086 / 662580$

Borkum, E., He, F., \& Linden, L. L. (2013). School libraries and language skills in Indian primary schools: A randomized evaluation of the Akshara Library program. Unpublished manuscript. Abdul Latif Jameel Poverty Action Lab (J-PAL). Cambridge, MA. 


\section{IMPROVING EDUCATION IN DEVELOPING COUNTRIES}

Bouguen, A., Filmer, D., Macours, K., \& Naudeau, S. (2014). Preschools and early childhood development in a second best world: Evidence from a scaled-up experiment in Cambodia. (Discussion Paper No. 10170). Centre for Economic Policy Research. London, UK.

Brooker, S., \& Halliday, K. (2015). Impact of malaria control and enhanced literacy instruction on educational outcomes among Kenyan school children: A multi-sectoral, prospective, randomised evaluation. Unpublished manuscript. International Initiative for Impact Evaluation (3ie). New Delhi, India.

Burde, D., \& Linden, L. L. (2013). The effect of village-based schools: Evidence from a randomized controlled trial in Afghanistan. American Economic Journal: Applied Economics, 5, 27-40. doi: 10.1257/app.5.3.27

Bursztyn, L., \& Coffman, L. C. (2012). The schooling decision: Family preferences, intergenerational conflict, and moral hazard in the Brazilian favelas. Journal of Political Economy, 120, 359-397. doi: 10.1086/666746

Buttenheim, A. M., Alderman, H., \& Friedman, J. (2011). Impact evaluation of school feeding programs in Lao PDR. (World Bank Policy Research Working Paper No. 5518). The World Bank. Washington, DC.

Cabezas, V., Cuesta, J. I., \& Gallego, F. A. (2011). Effects of short-term tutoring on cognitive and non-cognitive skills: Evidence from a randomized evaluation in Chile. Unpublished manuscript. Abdul Latif Jameel Poverty Action Lab (J-PAL). Santiago, Chile.

Camargo, B., Camelo, R., Firpo, S., \& Ponczek, V. (2011). Test score disclosure and school performance (Sao Paulo School of Economics Working Paper No. 11/2011). Sao Paulo, Brazil: Center for Applied Economics. 


\section{IMPROVING EDUCATION IN DEVELOPING COUNTRIES}

Carneiro, P., Koussihouèdé, O., Lahire, N., Meghir, C., \& Mommaerts, C. (2015).

Decentralizing education resources: School grants in Senegal. (NBER Working Paper No. 21063). National Bureau of Economic Research (NBER). Cambridge, MA.

Carrillo, P., Onofa, M., \& Ponce, J. (2011). Information technology and student achievement: Evidence from a randomized experiment in Ecuador. (IDB Working Paper No. IDB-WP223). Inter-American Development Bank. Washington, DC.

Chaudhury, N., \& Parajuli, D. (2010). Conditional cash transfers and female schooling: The impact of the female school stipend programme on public school enrolments in Punjab, Pakistan. Applied Economics, 42, 3565-3583. doi: 10.1080/00036840802167376

Chen, D., Glewwe, P., Kremer, M., \& Moulin, S. (2001). An interim report on a teacher attendance incentive program in Kenya. Unpublished manuscript. Development Economics Department, Harvard University Cambridge, MA.

Chen, X., Liu, C., Zhang, L., Shi, Y., \& Rozelle, S. (2010). Does taking one step back get you two steps forward? Grade retention and school performance in poor areas in rural China. International Journal of Educational Development, 30, 544-559. doi: 10.1016/j.ijedudev.2009.12.002

Chen, X., Shi, Y., Mo, D., Chu, J., Loyalka, P., \& Rozelle, S. (2013). Impact of a Senior High School Tuition Relief Program on Poor Junior High School Students in Rural China. China \& World Economy, 21, 80-97.

Chetty, R., Friedman, J. N., Hilger, N., Saez, E., Schanzenbach, D. W., \& Yagan, D. (2011). How does your kindergarten classroom affect your earnings? Evidence from project STAR. Quarterly Journal of Economics, 126, 1593-1660. doi: 10.1093/qje/qjr041 


\section{IMPROVING EDUCATION IN DEVELOPING COUNTRIES}

Chin, A. (2005). Can redistributing teachers across schools raise educational attainment?

Evidence from Operation Blackboard in India. Journal of Development Economics, 78, 384-405. doi: 10.1016/j.jdeveco.2004.09.004

Chitolina, L., Foguel, M. N., \& Menezes-Filho, N. (2013). The impact of the expansion of the Bolsa Família programme on the time allocation of youths and labour supply of adults (Working Paper No. 120). Sao Paulo, Brazil: International Policy Centre for Inclusive Growth.

Clarke, S. E., Jukes, M. C., Njagi, J. K., Khasakhala, L., Cundill, B., Otido, J., Crudder, C., Estambale, B. B., \& Brooker, S. (2008). Effect of intermittent preventive treatment of malaria on health and education in schoolchildren: A cluster-randomised, double-blind, placebo-controlled trial. The Lancet, 372, 127-138. doi: 10.1016/s0140-6736(08)61034-X

Conn, K. (2014). Identifying effective education interventions in Sub-Saharan Africa: A metaanalysis of rigorous impact evaluations. Unpublished manuscript. Columbia University. New York, NY.

Contreras, D. (2001). Evaluating a voucher system in Chile: Individual, family and school characteristics. Unpublished manuscript. Universidad de Chile, Facultad de Ciencias Económicas y Administrativas, Departamento de Economía. Santiago, Chile.

Cristia, J., Ibarrarán, P., Cueto, S., Santiago, A., \& Severín, E. (2012). Technology and child development: Evidence from the One Laptop per Child program. (Working Paper No. IDB-WP-304). Inter-American Development Bank. Washington, DC.

Cutler, D., Fung, W., Kremer, M., Singhal, M., \& Vogl, T. (2007). Mosquitoes: The long-term effects of malaria eradication in India (NBER Working Paper No. 13539). Cambridge, MA: National Bureau of Economic Research (NBER). 


\section{IMPROVING EDUCATION IN DEVELOPING COUNTRIES}

Dammert, A. C. (2009). Heterogeneous impacts of conditional cash transfers: Evidence from Nicaragua. Economic Development and Cultural Change, 58, 53-83. doi: $10.1086 / 605205$

Das, J., Dercon, S., Habyarimana, J., Krishnan, P., Muralidharan, K., \& Sundararaman, V. (2013). School inputs, household substitution, and test scores. American Economic Journal: Applied Economics, 5, 29-57. doi: 10.1257/app.5.2.29

De Hoop, K. (2010). Selective secondary education and school participation in Sub-Saharan Africa: Evidence from Malawi. (Tinbergen Institute Discussion Paper No. TI 2010041/2). Tinbergen Institute Amsterdam, the Netherlands.

De Janvry, A., Finan, F., Sadoulet, E., \& Vakis, R. (2006). Can conditional cash transfer programs serve as safety nets in keeping children at school and from working when exposed to shocks? Journal of Development Economics, 79, 349-373. doi:

10.1016/j.jdeveco.2006.01.013

de Laat, J., Kremer, M., \& Vermeersch, C. (2008). Teacher incentives and local participation. Unpublished manuscript. Harvard University. Cambridge, MA.

de Ree, J., Muralidharan, K., Pradhan, M., \& Rogers, F. H. (2015). Double for nothing? Experimental evidence on the impact of an unconditional teacher salary increase on student performance in Indonesia. Unpublished manuscript. The World Bank. Washington, DC.

Dhaliwal, I., Duflo, E., Glennerster, R., \& Tulloch, C. (2012). Comparative Cost-Effectiveness Analysis to Inform Policy in Developing Countries: A General Framework with Applications for Education. Abdul Latif Jameel Poverty Action Lab (J-PAL). Cambridge, MA. 


\section{IMPROVING EDUCATION IN DEVELOPING COUNTRIES}

Dinkelman, T., \& Martínez, A. C. (2013). Investing in schooling In Chile: The role of information about financial aid for higher education. Review of Economics and Statistics, 96, 244-257. doi: 10.1162/REST_a_00384

Dubois, P., \& Rubio-Codina, M. (2012). Child care provision: Semiparametric evidence from a randomized experiment in Mexico. Annals of Economics and Statistics, 105/106, 155184. doi: $10.2139 / \mathrm{ssrn} .1338713$

Duc, L. T., \& Baulch, B. (2012). Do extra classes improve cognitive test scores? Evidence from Vietnam. (Young Lives Working Paper No. 87). Young Lives. London, UK.

Duflo, E. (2001). Schooling and labor market consequences of school construction in Indonesia: Evidence from an unusual policy experiment. American Economic Review, 91, 795-813. doi: 10.1257/aer.91.4.795

Duflo, E., Berry, J., Mukerji, S., \& Shotland, M. (2015). A wide angle view of learning: Evaluation of the CCE and LEP programmes in Haryana, India. (Impact Evaluation Report No. 22). International Initiative for Impact Evaluation (3ie). New Delhi, India.

Duflo, E., Dupas, P., \& Kremer, M. (2011). Peer effects, teacher incentives, and the impact of tracking: Evidence from a randomized evaluation in Kenya. The American Economic Review, 101, 1739-1774. doi: 10.1257/aer.101.5.1739

---. (2015). School governance, teacher incentives, and pupil-teacher ratios: Experimental evidence from Kenyan primary schools. Journal of Public Economics, 123, 92-110. doi: 10.1016/j.jpubeco.2014.11.008

Duflo, E., Hanna, R., \& Ryan, S. P. (2012). Incentives work: Getting teachers to come to school. The American Economic Review, 102, 1241-1278. doi: 10.1257/aer.102.4.1241 


\section{IMPROVING EDUCATION IN DEVELOPING COUNTRIES}

Dumitrescu, A., Levy, D., Orfield, C., \& Sloan, M. (2011). Impact evaluation of Niger's IMAGINE program: Final report. Mathematica Policy Research. Washington, DC.

Evans, D. K., Kremer, M., \& Ngatia, M. (2009). The impact of distributing school uniforms on children's education in Kenya. Unpublished manuscript. The World Bank. Washington, DC.

Evans, D. K., \& Popova, A. (2015). What really works to improve learning in developing countries? An analysis of divergent findings in systematic reviews. (Policy Research Working Paper No. 7203). The World Bank. Washington, DC.

Fang, H., Eggleston, K. N., Rizzo, J. A., Rozelle, S., \& Zeckhauser, R. J. (2012). The returns to education in China: Evidence from the 1986 Compulsory Education Law. (NBER Working Paper No. 18189). National Bureau of Economic Research (NBER). Cambridge, MA.

Fernald, L. C., Gertler, P. J., \& Neufeld, L. M. (2008). Role of cash in conditional cash transfer programmes for child health, growth, and development: An analysis of Mexico's Oportunidades. The Lancet, 371, 828-837. doi: 10.1016/s0140-6736(08)60382-7

---. (2009). 10-year effect of Oportunidades, Mexico's conditional cash transfer programme, on child growth, cognition, language, and behaviour: A longitudinal follow-up study. The Lancet, 374, 1997-2005. doi: 10.1016/s0140-6736(09)61676-7

Fernando, D., De Silva, D., Carter, R., Mendis, K. N., \& Wickremasinghe, R. (2006). A randomized, double-blind, placebo-controlled, clinical trial of the impact of malaria prevention on the educational attainment of school children. The American Journal of Tropical Medicine and Hygiene, 74, 386-393. 


\section{IMPROVING EDUCATION IN DEVELOPING COUNTRIES}

Ferreira, F. H., Filmer, D., \& Schady, N. (2009). Own and sibling effects of conditional cash transfer programs: Theory and evidence from Cambodia. (Policy Research Working Paper No. 5001). The World Bank. Washington, DC.

Filmer, D., \& Schady, N. (2008). Getting girls into school: Evidence from a scholarship program in Cambodia. Economic Development and Cultural Change, 96, 150-157. doi: $10.1596 / 1813-9450-3910$

---. (2014). The medium-term effects of scholarships in a low-income country. Journal of Human Resources, 49, 663-694. doi: 10.1353/jhr.2014.0022

Freeman, M. C., Greene, L. E., Dreibelbis, R., Saboori, S., Muga, R., Brumback, B., \& Rheingans, R. (2012). Assessing the impact of a school - based water treatment, hygiene and sanitation programme on pupil absence in Nyanza Province, Kenya: A cluster randomized trial. Tropical Medicine \& International Health, 17, 380-391. doi: 10.1111/j.1365-3156.2011.02927.x

Gajigo, O. (2014). Closing the education gender gap: Estimating the impact of Girls' Scholarship Program in The Gambia. Education Economics, 1-22. doi:

$10.1080 / 09645292.2014 .985287$

Galiani, S., \& McEwan, P. (2013). The heterogeneous impact of conditional cash transfers. Journal of Public Economics, 103, 85-96. doi: 10.1016/j.jpubeco.2013.04.004

Gertler, P. J., Patrinos, H. A., \& Rubio-Codina, M. (2012). Empowering parents to improve education: Evidence from rural Mexico. Journal of Development Economics, 99, 68-79. doi: 10.1596/1813-9450-3935

Githua, B. N., \& Nyabwa, R. A. (2008). Effects of advance organiser strategy during instruction on secondary school students’ mathematics achievement in Kenya’s Nakuru district. 


\section{IMPROVING EDUCATION IN DEVELOPING COUNTRIES}

International Journal of Science and Mathematics Education, 6, 439-457. doi:

10.1007/s10763-006-9037-8

Glewwe, P., Hanushek, E. A., Humpage, S. D., \& Ravina, R. (2014). School resources and educational outcomes in developing countries: A review of the literature from 1990 to 2010. In P. Glewwe (Ed.), Education Policy in Developing Countries. Chicago, IL and London, UK: University of Chicago Press.

Glewwe, P., Ilias, N., \& Kremer, M. (2010). Teacher incentives. American Economic Journal: Applied Economics, 2, 205-227. doi: 10.1257/app.2.3.205

Glewwe, P., Kremer, M., \& Moulin, S. (2009). Many children left behind? Textbooks and test scores in Kenya. American Economic Journal: Applied Economics, 1, 112-135. doi: 10.1257/app.1.1.112

Glewwe, P., Kremer, M., Moulin, S., \& Zitzewitz, E. (2004). Retrospective vs. prospective analyses of school inputs: The case of flip charts in Kenya. Journal of Development Economics, 74, 251-268. doi: 10.1016/j.jdeveco.2003.12.010

Glewwe, P., \& Maïga, E. W. (2011). The impacts of school management reforms in Madagascar: Do the impacts vary by teacher type? Journal of development effectiveness, 3, 435-469. doi: 10.1080/19439342.2011.604729

Glewwe, P., \& Olinto, P. (2004). Evaluating the impact of conditional cash transfers on schooling: An experimental analysis of Honduras’ PRAF program. Unpublished manuscript. University of Minnesota. Minneapolis, MN.

Glewwe, P., Park, A., \& Zhao, M. (2014). A better vision for development: Eyeglasses and academic performance in rural primary schools in China. Abdul Latif Jameel Poverty Action Lab (J-PAL). Cambridge, MA. 


\section{IMPROVING EDUCATION IN DEVELOPING COUNTRIES}

Grigorenko, E. L., Sternberg, R. J., Jukes, M., Alcock, K., Lambo, J., Ngorosho, D., Nokes, C., \& Bundy, D. A. (2006). Effects of antiparasitic treatment on dynamically and statically tested cognitive skills over time. Journal of Applied Developmental Psychology, 27, 499526. doi: 10.1016/j.appdev.2006.08.005

Guerrero, G., Leon, J., Zapata, M., Sugimaru, C., \& Cueto, S. (2012). What works to improve teacher attendance in developing countries? A systematic review. Unpublished manuscript. EPPI-Centre, Social Science Research Unit, Institute of Education, University of London. London, UK.

Hallfors, D., Cho, H., Rusakaniko, S., Iritani, B., Mapfumo, J., \& Halpern, C. (2011). Supporting adolescent orphan girls to stay in school as HIV risk prevention: Evidence from a randomized controlled trial in Zimbabwe. American journal of public health, 101, 10821088.

Hamazaki, K., Syafruddin, D., Tunru, I. S., Azwir, M. F., Puji, B. A., Sawazaki, S., \& Hamazaki, T. (2008). The effects of docosahexaenoic acid-rich fish oil on behavior, school attendance rate and malaria infection in school children: A double-blind, randomized, placebo-controlled trial in Lampung, Indonesia. Asia Pacific Journal of Clinical Nutrition, 17, 258-263. doi: 10.1097/00004703-200208000-00022

Hasan, A. (2010). Gender-targeted conditional cash transfers: Enrollment, spillover effects and instructional quality. (Policy Research Working Paper No. 5257). The World Bank. Washington, DC.

He, F., Linden, L., \& MacLeod, M. (2008). How to teach English in India: Testing the relative productivity of instruction methods within the Pratham English language education program. Unpublished manuscript. Columbia University. New York, NY. 


\section{IMPROVING EDUCATION IN DEVELOPING COUNTRIES}

He, F., Linden, L. L., \& MacLeod, M. (2009). A better way to teach children to read? Evidence from a randomized controlled trial. Unpublished manuscript. Abdul Latif Jameel Poverty Action Lab (J-PAL). Cambridge, MA.

Hsieh, C.-T., \& Urquiola, M. (2006). The effects of generalized school choice on achievement and stratification: Evidence from Chile's voucher program. Journal of Public Economics, 90, 1477-1503. doi: 10.1016/j.jpubeco.2005.11.002

Huan, W., Chu, J., Loyalka, P., Tao, X., Shi, Y., Qu, Q., Yang, C., \& Rozelle, S. (2014). Can school counseling reduce school dropout in developing countries? (REAP Working Paper No. 275). Rural Education Action Program (REAP). Stanford, CA.

Huang, W., Mo, D., Shi, Y., Zhang, L., Boswell, M., \& Rozelle, S. (2014). Computer technology in education: Evidence from a pooled study of computer assisted learning programs among rural students in China. (REAP Working Paper No. 278). Rural Education Action Program (REAP). Stanford, CA.

Jackson, C. K. (2010). Do students benefit from attending better schools? Evidence from rulebased student assignments in Trinidad and Tobago The Economic Journal, 120, 13991429. doi: 10.1111/j.1468-0297.2010.02371.x

---. (2012). Single-sex schools, student achievement, and course selection: Evidence from rulebased student assignments in Trinidad and Tobago. Journal of Public Economics, 96, 173-187. doi: 10.1016/j.jpubeco.2011.09.002

---. (2013). Can higher-achieving peers explain the benefits to attending selective schools? Evidence from Trinidad and Tobago. Journal of Public Economics, 108, 63-77. doi: 10.1016/j.jpubeco.2013.09.007 


\section{IMPROVING EDUCATION IN DEVELOPING COUNTRIES}

Jensen, R. (2010). The (perceived) returns to education and the demand for schooling. Quarterly Journal of Economics, 125, 515-548. doi: 10.1162/qjec.2010.125.2.515

---. (2012). Do labor market opportunities affect young women's work and family decisions? Experimental evidence from India. The Quarterly Journal of Economics, 127, 753-792. doi: 10.1093/qje/qjs002

Jinabhai, C. C., Taylor, M., Coutsoudis, A., Coovadia, H. M., Tomkins, A. M., \& Sullivan, K. R. (2001). A randomized controlled trial of the effect of antihelminthic treatment and micronutrient fortification on health status and school performance of rural primary school children. Annals of Tropical Paediatrics: International Child Health, 21, 319-333. doi: 10.1080/07430170120093508

Jukes, M. C., Pinder, M., Grigorenko, E. L., Smith, H. B., Walraven, G., Bariau, E. M., Sternberg, R. J., Drake, L. J., Milligan, P., \& Cheung, Y. B. (2006). Long-term impact of malaria chemoprophylaxis on cognitive abilities and educational attainment: Follow-up of a controlled trial. PLoS clinical trials, 1, e19. doi: 10.1371/journal.pctr.0010019

Kagitcibasi, C., Sunar, D., \& Bekman, S. (2001). Long-term effects of early intervention: Turkish low-income mothers and children. Applied Developmental Psychology, 22, 333361. doi: 10.1016/s0193-3973(01)00071-5

Kane, T. J., \& Staiger, D. O. (2001). Improving school accountability measures. (NBER Working Paper No. 8156). National Bureau of Economic Research (NBER). Cambridge, MA.

---. (2002). The promise and pitfalls of using imprecise school accountability measures. The Journal of Economic Perspectives, 16, 91-114. doi: 10.1257/089533002320950993 


\section{IMPROVING EDUCATION IN DEVELOPING COUNTRIES}

Karlan, D., \& Linden, L. L. (2013). Loose knots: Strong versus weak commitments to save for education in Uganda. (NBER Working Paper No. 19863). National Bureau of Economic Research (NBER). Cambridge, MA.

Kazianga, H., De Walque, D., \& Alderman, H. (2012). Educational and child labour impacts of two food-for-education schemes: Evidence from a randomised trial in rural Burkina Faso. Journal of African Economies, 21, 723-760. doi: 10.1093/jae/ejs010

Kazianga, H., Levy, D., Linden, L. L., \& Sloan, M. (2013). The effects of "girl-friendly" schools: Evidence from the BRIGHT school construction program in Burkina Faso. American Economic Journal: Applied Economics, 5, 41-62. doi: 10.1257/app.5.3.41

Kemple, J. J., \& Willner, C. J. (2008). Career academies: Long-term impacts on labor market outcomes, educational attainment, and transitions to adulthood. MDRC. New York, NY.

Kleiman-Weiner, M., Luo, R., Zhang, L., Shi, Y., Medina, A., \& Rozelle, S. (2013). Eggs versus chewable vitamins: Which intervention can increase nutrition and test scores in rural China? China Economic Review, 24, 165-176. doi: 10.1016/j.chieco.2012.12.005

Kremer, M., Brannen, C., \& Glennerster, R. (2013). The challenge of education and learning in the developing world. Science, 340, 297-300. doi: 10.1126/science.1235350

Kremer, M., Miguel, E., \& Thornton, R. (2009). Incentives to learn. The Review of Economics and Statistics, 91, 437-456. doi: 10.1162/rest.91.3.437

Kremer, M., Moulin, S., \& Namunyu, R. (2003). Decentralization: A cautionary tale. Unpublished manuscript. Abdul Latif Jameel Poverty Action Lab (J-PAL). Cambridge, MA. 


\section{IMPROVING EDUCATION IN DEVELOPING COUNTRIES}

Krishnaratne, S., White, H., \& Carpenter, E. (2013). Quality education for all children? What works in education in developing countries. (Working Paper No. 20). International Initiative for Impact Evaluation (3ie). New Delhi, India.

Lai, F., Luo, R., Zhang, L., Huang, X., \& Rozelle, S. (forthcoming). Does computer-assisted learning improve learning outcomes? Evidence from a randomized experiment in migrant schools in Beijing. Economics of Education Review. doi:

10.1016/j.econedurev.2015.03.005

Lai, F., Zhang, L., Hu, X., Qu, Q., Shi, Y., Qiao, Y., Boswell, M., \& Rozelle, S. (2013).

Computer assisted learning as extracurricular tutor? Evidence from a randomised experiment in rural boarding schools in Shaanxi. Journal of development effectiveness, 5, 208-231. doi: 10.1080/19439342.2013.780089

Lai, F., Zhang, L., Qu, Q., Hu, X., Shi, Y., Boswell, M., \& Rozelle, S. (2012). Does computerassisted learning improve learning outcomes? Evidence from a randomized experiment in public schools in rural minority areas in Qinghai, China. (REAP working paper No. 237). Rural Education Action Program (REAP). Stanford, CA.

Lassibille, G., Tan, J.-P., Jesse, C., \& Nguyen, T. V. (2010). Managing for results in primary education in Madagascar: Evaluating the impact of selected workflow interventions. The World Bank Economic Review, 1-27. doi: 10.1093/wber/lhq009

Lavy, V. (2009). Performance pay and teachers' effort, productivity, and grading ethics. The American Economic Review, 99, 1979-2011. doi: 10.2307/25592544

---. (2010). Effects of free choice among public schools. The Review of Economic Studies, 77, 1164-1191. doi: 10.1111/j.1467-937X.2009.00588.x 


\section{IMPROVING EDUCATION IN DEVELOPING COUNTRIES}

---. (2012). Expanding school resources and increasing time on task: Effects of a policy experiment in Israel on student academic achievement and behavior. (NBER Working Paper No. 18369). National Bureau of Economic Research (NBER). Cambridge, MA.

---. (2013). Gender differences in market competitiveness in a real workplace: Evidence from performance - based pay tournaments among teachers. The Economic Journal, 123, 540573. doi: $10.3386 / w 14338$

Lavy, V., \& Schlosser, A. (2005). Targeted remedial education for underperforming teenagers: Costs and benefits. Journal of Labor Economics, 23, 839-874. doi: 10.1086/491609

Levy, D., \& Ohls, J. (2007). Evaluation of Jamaica’s PATH program: Final report. Washington, DC: Mathematica Policy Research.

Li, T., Han, L., Zhang, L., \& Rozelle, S. (2014). Encouraging classroom peer interactions: Evidence from Chinese migrant schools. Journal of Public Economics, 111, 29-45. doi: 10.1016/j.jpubeco.2013.12.014

Linden, L. L. (2008). Complement or substitute? The effect of technology on student achievement in India. Unpublished manuscript. Abdul Latif Jameel Poverty Action Lab (J-PAL). Cambridge, MA.

Liu, C., Yi, H., Luo, R., Bai, Y., Zhang, L., Shi, Y., . . Rozelle, S. (2013). The effect of early commitment of financial aid on matriculation to senior high school among poor junior high students in rural China. (REAP Working Paper No. 254). Rural Education Action Program (REAP). Stanford, CA.

Liu, C., Zhang, L., Luo, R., Rozelle, S., \& Loyalka, P. (2010). The effect of primary school mergers on academic performance of students in rural China. International Journal of Educational Development, 30, 570-585. doi: 10.1016/j.ijedudev.2010.05.003 


\section{IMPROVING EDUCATION IN DEVELOPING COUNTRIES}

Loyalka, P., Liu, C., Song, Y., Yi, H., Huang, X., Wei, J., Zhang, L., Shi, Y., Chu, J., \& Rozelle, S. (2013). Can information and counseling help students from poor rural areas go to high school? Evidence from China. Journal of Comparative Economics, 41, 1012-1025. doi: 10.1016/j.jpubeco.2013.12.014

Loyalka, P., Wei, J., \& Zhong, W. (2015). The impacts of building elite high schools for students from disadvantaged areas. Economic Development and Cultural Change, 63, 393-422. doi: 10.1086/678992

Lucas, A. M., \& Mbiti, I. M. (2012). Access, sorting, and achievement: The short-run effects of free primary education in Kenya. American Economic Journal: Applied Economics, 4, 226-253. doi: 10.1257/app.4.4.226

Lucas, A. M., McEwan, P. J., Ngware, M., \& Oketch, M. (2014). Improving early-grade literacy in East Africa: Experimental evidence from Kenya and Uganda. Journal of Policy Analysis and Management, 33, 950-976. doi: 10.1002/pam.21782

Ludwig, J., \& Miller, D. L. (2007). Does Head Start improve children's life chances? Evidence from a regression discontinuity design. Quarterly Journal of Economics, 122, 159-208. doi: 10.1162/qjec.122.1.159

Luo, R., Shi, Y., Zhang, L., Liu, C., Rozelle, S., Sharbono, B., Yue, A., Zhao, Q., \& Martorell, R. (2012). Nutrition and educational performance in rural China's elementary schools: Results of a randomized control trial in Shaanxi Province. Economic Development and Cultural Change, 60. doi: 10.1086/665606

Ma, X., Zhou, Z., Yi, H., Pang, X., Shi, Y., Chen, Q., Meltzer, M. E., le Cessie, S., He, M., Rozelle, S., Liu, Y., \& Congdon, N. (2014). Effect of providing free glasses on children's educational outcomes in China: The Seeing is Learning cluster-randomized controlled 


\section{IMPROVING EDUCATION IN DEVELOPING COUNTRIES}

trial. Unpublished manuscript. Stanford University Rural Education Action Program (REAP). Stanford, CA.

Macours, K., Schady, N., \& Vakis, R. (2012). Cash transfers, behavioral changes, and cognitive development in early childhood: Evidence from a randomized experiment. American Economic Journal: Applied Economics, 4, 247-273. doi: 10.1257/app.4.2.247

Mahawithanage, S. T. C., Kannangara, K. K. N. P., Wickremasinghe, R., Chandrika, U. G., Jansz, E. R., Karunaweera, N. D., \& Wickremasinghe, A. R. (2007). Impact of vitamin A supplementation on health status and absenteeism of school children in Sri Lanka. Asia Pacific Journal of Clinical Nutrition, 16, 94-102.

Malamud, O., \& Pop-Eleches, C. (2011). Home computer use and the development of human capital. The Quarterly Journal of Economics, 126, 987-1027. doi: 10.1093/qje/qjr008

Maluccio, J., Hoddinott, J., Behrman, J. R., Martorell, R., Quisumbing, A., \& Stein, A. D. (2009). The impact of nutrition during early childhood on education among Guatemalan adults. (PIER Working Paper No. 06).

Maluccio, J. A., \& Flores, R. (2005). Impact evaluation of a conditional cash transfer program: The Nicaraguan Red de Protección Social Unpublished manuscript: International Food Policy Research Institute.

Maluccio, J. A., Murphy, A., \& Regalia, F. (2010). Does supply matter? Initial schooling conditions and the effectiveness of conditional cash transfers for grade progression in Nicaragua. Journal of development effectiveness, 2, 87-116. doi:

$10.1080 / 19439340903584085$

Manger, M. S., McKenzie, J. E., Winichagoon, P., Gray, A., Chavasit, V., Pongcharoen, T., Gowachirapant, S., Ryan, B., Wasantwisut, E., \& Gibson, R. S. (2008). A micronutrient- 


\section{IMPROVING EDUCATION IN DEVELOPING COUNTRIES}

fortified seasoning powder reduces morbidity and improves short-term cognitive function, but has no effect on anthropometric measures in primary school children in northeast Thailand: A randomized controlled trial. The American Journal of Clinical Nutrition, 87, 1715-1722.

Manley, J., Fernald, L., \& Gertler, P. (2015). Wealthy, healthy and wise: Does money compensate for being born into difficult conditions? Applied Economics Letters, 22, 121126. doi: $10.1080 / 13504851.2014 .929618$

Martinez, S., Naudeau, S., \& Pereira, V. (2013). The promise of preschool in Africa: A randomized impact evaluation of early childhood development in rural Mozambique. Unpublished manuscript. International Initiative for Impact Evaluation (3ie). . New Delhi, India.

Masino, S., \& Niño-Zarazúa, M. (2015). What works to improve the quality of student learning in developing countries? (WIDER Working Paper No. 2015/033). World Institute for Development Economics Research. Helsinki, Finland.

McEwan, P. (2013). The impact of Chile’s school feeding program on education outcomes. Economics of Education Review, 32, 122-139. doi: 10.1016/j.econedurev.2012.08.006

---. (2014). Improving learning in primary schools of developing countries: A meta-analysis of randomized experiments. Review of Educational Research, $X X, 1-42$. doi: $10.3102 / 0034654314553127$

McEwan, P., \& Santibáñez, L. (2005). Teacher and principal incentives in Mexico. In E. Vegas (Ed.), Incentives to improve teaching. Washington, DC: The World Bank. 


\section{IMPROVING EDUCATION IN DEVELOPING COUNTRIES}

Menezes-Filho, N., \& Pazello, E. (2007). Do teachers’ wages matter for proficiency? Evidence from a funding reform in Brazil. Economics of Education Review, 26, 660-672. doi: 10.1016/j.econedurev.2007.08.003

Miguel, E., \& Kremer, M. (2004). Worms: Identifying impacts on education and health in the presence of treatment externalities. Econometrica, 72, 159-217. doi: 10.1111/j.14680262.2004.00481.x

Mizala, A., \& Urquiola, M. (2013). School markets: The impact of information approximating schools’ effectiveness. Journal of Development Economics, 103, 313-335. doi: 10.3386/w13676

Mo, D., Luo, R., Liu, C., Zhang, H., Zhang, L., Medina, A., \& Rozelle, S. (2014). Text messaging and its impacts on the health and education of the poor: Evidence from a field experiment in rural China. World Development, 64, 766-780. doi: 10.1016/j.worlddev.2014.07.015

Mo, D., Swinnen, J., Zhang, L., Yi, H., Qu, Q., Boswell, M., \& Rozelle, S. (2013). Can one-toone computing narrow the digital divide and the educational gap in China? The case of Beijing migrant schools. World Development, 46, 14-29. doi:

10.1016/j.worlddev.2012.12.019

Mo, D., Zhang, L., Luo, R., Qu, Q., Huang, W., Wang, J., Qiao, Y., Boswell, M., \& Rozelle, S. (2014). Integrating computer-assisted learning into a regular curriculum: Evidence from a randomised experiment in rural schools in Shaanxi. Journal of development effectiveness, 6, 300-323. doi: 10.1080/19439342.2014.911770

Mo, D., Zhang, L., Wang, J., Huang, W., Shi, Y., Boswell, M., \& Rozelle, S. (2014). The persistence of gains in learning from computer assisted learning (CAL): Evidence from a 


\section{IMPROVING EDUCATION IN DEVELOPING COUNTRIES}

randomized experiment in rural schools in Shaanxi province in China. (REAP Working Paper No. 268). Rural Education Action Program (REAP). Stanford, CA.

Mo, D., Zhang, L., Yi, H., Luo, R., Rozelle, S., \& Brinton, C. (2013). School dropouts and conditional cash transfers: Evidence from a randomised controlled trial in rural China's junior high schools. The Journal of Development Studies, 49, 190-207. doi:

10.2139/ssrn.1859283

Mocan, N. H., \& Cannonier, C. (2012). Empowering women through education: Evidence from Sierra Leone. (NBER Working Paper No. 18016). National Bureau of Economic Research (NBER). Cambridge, MA.

Muralidharan, K., \& Prakash, N. (2013). Cycling to school: Increasing secondary school enrollment for girls in India. (Working Paper No. 19305). National Bureau of Economic Research (NBER). Cambridge, MA.

Muralidharan, K., \& Sundararaman, V. (2010). The impact of diagnostic feedback to teachers on student learning: Experimental evidence from India. The Economic Journal, 120, F187F203. doi: 10.1111/j.1468-0297.2010.02373.x

---. (2011). Teacher performance pay: Experimental evidence from India. The Journal of Political Economy, 119, 39-77. doi: 10.1086/659655

---. (2013). Contract teachers: Experimental evidence from India. (Working Paper No. 19440). National Bureau of Economic Research (NBER). Cambridge, MA.

---. (2015). The aggregate effect of school choice: Evidence from a two-stage experiment in India. The Quarterly Journal of Economics, 130, 1011-1066. doi: 10.1093/qje/qjv013 


\section{IMPROVING EDUCATION IN DEVELOPING COUNTRIES}

Naslund-Hadley, E., Parker, S. W., \& Hernandez-Agramonte, J. M. (2014). Fostering early math comprehension: Experimental evidence from Paraguay. Global Education Review, 1, 135-154. doi: 10.1080/13600818.2014.887061

Nguyen, T. (2009). Information, role models and perceived returns to education: Experimental evidence from Madagascar. Unpublished manuscript. Massachusetts Institute of Technology. Cambridge, MA.

Oosterbeek, H., Ponce, J., \& Schady, N. (2008). The impact of cash transfers on school enrollment: Evidence from Ecuador (Policy Research Working Paper No. TI 2008037/4). Washington, DC: The World Bank.

Orkin, K. (2013). The effect of lengthening the school day on children's achievement in Ethiopia. (Working Paper No. 119). Young Lives. London, UK.

Osendarp, S. J., Baghurst, K. I., Bryan, J., Calvaresi, E., Hughes, D., Hussaini, M., Karyadi, E., van Klinken, B. J.-W., van der Knaap, H. C., Lukito, W., Mikarsa, H., Transler, C., \& Wilson, C. (2007). Effect of a 12-mo micronutrient intervention on learning and memory in well-nourished and marginally nourished school-aged children: 2 parallel, randomized, placebo-controlled studies in Australia and Indonesia. The American Journal of Clinical Nutrition, 86, 1082-1093.

Oster, E., \& Thornton, R. (2011). Menstruation, sanitary products, and school attendance: Evidence from a randomized evaluation. American Economic Journal: Applied Economics, 3, 91-100. doi: 10.1257/app.3.1.91

Pandey, P., Goyal, S., \& Sundararaman, V. (2009). Community participation in public schools: Impact of information campaigns in three Indian states. Education Economics, 17, 355375. doi: 10.1080/09645290903157484 


\section{IMPROVING EDUCATION IN DEVELOPING COUNTRIES}

Perova, E., \& Vakis, R. (2012). 5 years in Juntos: New evidence on the program’s short and long-Term Impacts. Economía, 35, 53-82.

Piper, B. (2009). Integrated education program: Impact study of SMRS using early grade reading assessment in three provinces in South Africa. Research Triangle Park, NC: RTI International.

Piper, B., \& Korda, M. (2011). EGRA plus: Liberia. Program evaluation report. Research Triangle Park, NC: RTI International.

Pop-Eleches, C., \& Urquiola, M. (2013). Going to a better school: Effects and behavioral responses. American Economic Review, 103, 1289-1324. doi: 10.1257/aer.103.4.1289

Pradhan, M., Suryadarma, D., Beatty, A., Wong, M., Gaduh, A., Alisjahbana, A., \& Artha, R. P. (2014). Improving educational quality through enhancing community participation: Results from a randomized field experiment in Indonesia. American Economic Journal: Applied Economics, 6, 105-126. doi: /10.2139/ssrn.1862143

Pritchett, L., \& Sandefur, J. (2013). Context matters for size: Why external validity claims and development practice don’t mix. (Working Paper No. 336). Center for Global Development (CGD). Washington, DC.

Ravallion, M., \& Wodon, Q. (2000). Does child labour displace schooling? Evidence on behavioural responses to an enrollment subsidy. The Economic Journal, 110, 158-175. doi: 10.1111/1468-0297.00527

Reinikka, R., \& Svensson, J. (2011). The power of information in public services: Evidence from education in Uganda. Journal of Public Economics, 95, 956-966. doi: 10.1016/j.jpubeco.2011.02.006 


\section{IMPROVING EDUCATION IN DEVELOPING COUNTRIES}

Rico, J. A., Kordas, K., López, P., Rosado, J. L., Vargas, G. G., Ronquillo, D., \& Stoltzfus, R. J. (2006). Efficacy of Iron and/or Zinc Supplementation on Cognitive Performance of LeadExposed Mexican Schoolchildren: A Randomized, Placebo-Controlled Trial. Pediatrics, 117, e518-e527.

Rocha, R., \& Soares, R. R. (2010). Evaluating the impact of community-based health interventions: Evidence from Brazil's Family Health program. Health Economics, 19, 126-158. doi: 10.1002/hec.1607

Rogers, J., Chanturidze, T., \& MacAuslan, I. (2013). Kazakhstan: External evaluation, BOTA programs Unpublished manuscript. Oxford, United Kingdom: Oxford Policy Management Limited.

Rosero, J., \& Oosterbeek, H. (2011). Trade-offs between different early childhood interventions: Evidence from Ecuador. Tinbergen Institute Discussion Paper, No. 11-102/3. Tinbergen Institute. Amsterdam, the Netherlands.

Sabarwal, S., Evans, D., \& Marshak, A. (2013). The permanent textbook hypothesis: School inputs and student outcomes in Sierra Leone. (Policy Research Working Paper No. 7021). The World Bank. Washington, DC.

Schady, N., \& Araujo, M. C. (2008). Cash transfers, conditions, and school enrollment in Ecuador. Economía, 8, 43-70. doi: 10.1353/eco.0.0004

Schultz, P. T. (2004). School subsidies for the poor: Evaluating the Mexican Progresa poverty program. Journal of Development Economics, 74, 199-250. doi:

10.1016/j.jdeveco.2003.12.009

Sharma, D. (2010). The Impact of financial incentives on academic achievement and household behavior: Evidence from a randomized trial in Nepal. Unpublished manuscript. 


\section{IMPROVING EDUCATION IN DEVELOPING COUNTRIES}

Department of Agricultural, Environmental, and Development Economics. The Ohio State University. Columbus, $\mathrm{OH}$.

Skoufias, E. (2001). PROGRESA and its impacts on the human capital and welfare of households in rural Mexico: A synthesis of the results of an evaluation by IFPRI Unpublished manuscript. Washington, DC: International Food Policy Research Institute.

Skoufias, E., Parker, S. W., Behrman, J. R., \& Pessino, C. (2001). Conditional cash transfers and their impact on child work and schooling: Evidence from the Progresa program in Mexico. Economía, 45-96. doi: 10.1353/eco.2001.0016

Solon, F. S., Sarol, J. N., Bernardo, A. B., Solon, J. A. A., Mehansho, H., Sanchez-Fermin, L. E., Wambangco, L. S., \& Juhlin, K. D. (2003). Effect of a multiple-micronutrient-fortified fruit powder beverage on the nutrition status, physical fitness, and cognitive performance of schoolchildren in the Philippines. Food \& Nutrition Bulletin, 24, S129-S140.

Sparrow, R. (2007). Protecting education for the poor in times of crisis: An evaluation of a scholarship programme in Indonesia. Oxford Bulletin of Economics and Statistics, 69, 99122. doi: 10.1111/j.1468-0084.2006.00438.x

Spohr, C. A. (2003). Formal schooling and workforce participation in a rapidly developing economy: Evidence from “compulsory” junior high school in Taiwan. Journal of Development Economics, 70, 291-327. doi: 10.1016/s0304-3878(02)00099-8

Spratt, J., King, S., \& Bulat, J. (2013). Independent evaluation of the effectiveness of Institut pour l'Education Populaire’s “Read-Learn-Lead”(RLL) program in Mali. Unpublished manuscript. RTI International. Research Triangle Park, NC.

Sylvia, S., Luo, R., Zhang, L., Shi, Y., Medina, A., \& Rozelle, S. (2013). Do you get what you pay for with school-based health programs? Evidence from a child nutrition experiment 


\section{IMPROVING EDUCATION IN DEVELOPING COUNTRIES}

in rural China. Economics of Education Review, 37, 1-12. doi:

10.1016/j.econedurev.2013.07.003

Tieffenberg, J. A., Wood, E. I., Alonso, A., Tossutti, M. S., \& Vicente, M. F. (2000). A randomized field trial of Acindes: A child-centered training model for children with chronic illness (asthma and epilepsy). Journal of Urban Health, 77, 280-297. doi: 10.1007/bf02390539

Todd, P., \& Wolpin, K. I. (2003). Assessing the impact of a school subsidy program in Mexico: Using a social experiment to validate a dynamic behavioral model of child schooling and fertility. American Economic Review, 96, 1384-1417. doi: 10.1257/aer.96.5.1384

Urquiola, M. (2006). Identifying class size effects in developing countries: Evidence from rural Bolivia. Review of Economics and Statistics, 88, 171-177. doi: 10.1596/1813-9450-2711

Urquiola, M., \& Verhoogen, E. (2009). Class-size caps, sorting, and the regression-discontinuity design. American Economic Review, 99, 179-215. doi: 10.1257/aer.99.1.179

Van Staden, A. (2011). Put reading first: Positive effects of direct instruction and scaffolding for ESL learners struggling with reading. Perspectives in Education, 29, 10-21.

Vermeersch, C., \& Kremer, M. (2004). School meals, educational achievement, and school competition: Evidence from a randomized evaluation. Unpublished manuscript. The World Bank. Washington, DC.

Vivalt, E. (2015). How much can we generalize from impact evaluations? Unpublished manuscript. New York University. New York, NY.

Wachanga, S. W., \& Mwangi, J. G. (2004). Effects of the cooperative class experiment teaching method on secondary school students' chemistry achievement in Kenya's Nakuru district. International Education Journal, 5, 26-36. 


\section{IMPROVING EDUCATION IN DEVELOPING COUNTRIES}

Walker, S. P., Chang, S. M., Powell, C. A., \& Grantham-McGregor, S. M. (2005). Effects of early childhood psychosocial stimulation and nutritional supplementation on cognition and education in growth-stunted Jamaican children: Prospective cohort study. The Lancet, 366, 1804-1807. doi: 10.1016/s0140-6736(05)67574-5

Whaley, S. E., Sigman, M., Neumann, C., Bwibo, N., Guthrie, D., Weiss, R. E., Alber, S., \& Murphy, S. P. (2003). The impact of dietary intervention on the cognitive development of Kenyan school children. Journal of Nutrition, 133, 3965S-3971S.

Wong, H. L., Luo, R., Zhang, L., \& Rozelle, S. (2013). The impact of vouchers on preschool attendance and elementary school readiness: A randomized controlled trial In rural China. Economics of Education Review, 35, 53-65. doi: 10.1016/j.econedurev.2013.03.004

Yang, Y., Zhang, L., Zeng, J., Pang, X., Lai, F., \& Rozelle, S. (2013). Computers and the academic performance of elementary school-aged girls in China's poor communities. Computers \& Education, 60, 335-346. doi: 10.1016/j.compedu.2012.08.011

Yi, H., Song, Y., Liu, C., Huang, X., Zhang, L., Bai, Y., Shi, Y., Yang, C., Wang, H., Loyalka, P., Chu, J., \& Rozelle, S. (2012). Giving Kids a Head Start: The Impact of Early Commitment of Financial Aid on Poor Seventh Grade Students in Rural China. Stanford, CA: Stanford University Rural Education Action Program (REAP).

Yoshikawa, H., Leyva, D., Snow, C. E., Treviño, E., Arbour, M. C., Barata, M. C., Weiland, C., Gómez, C., Moreno, L., Rolla, A., \& D'Sa, N. (2015). Experimental impacts of a teacher professional development program in Chile on preschool classroom quality and child outcomes. Journal of Developmental Psychology, 51, 309-322. doi: 10.1037/a0038785.supp 


\section{IMPROVING EDUCATION IN DEVELOPING COUNTRIES}

Yue, A., Shi, Y., Chang, F., Yang, C., Wang, H., Yi, H., Luo, R., Liu, C., Zhang, L., \& Chu, J. (2012). Dormitory management and boarding students in China's rural elementary schools. (REAP Working Paper No. 242). Rural Education Action Program (REAP). Stanford, CA.

Zhang, L., Lai, F., Pang, X., Yi, H., \& Rozelle, S. (2013). The impact of teacher training on teacher and student outcomes: Evidence from a randomised experiment in Beijing migrant schools. Journal of development effectiveness, 5, 339-358. doi: $10.1080 / 19439342.2013 .807862$ 
Figure 1. Search and review process.

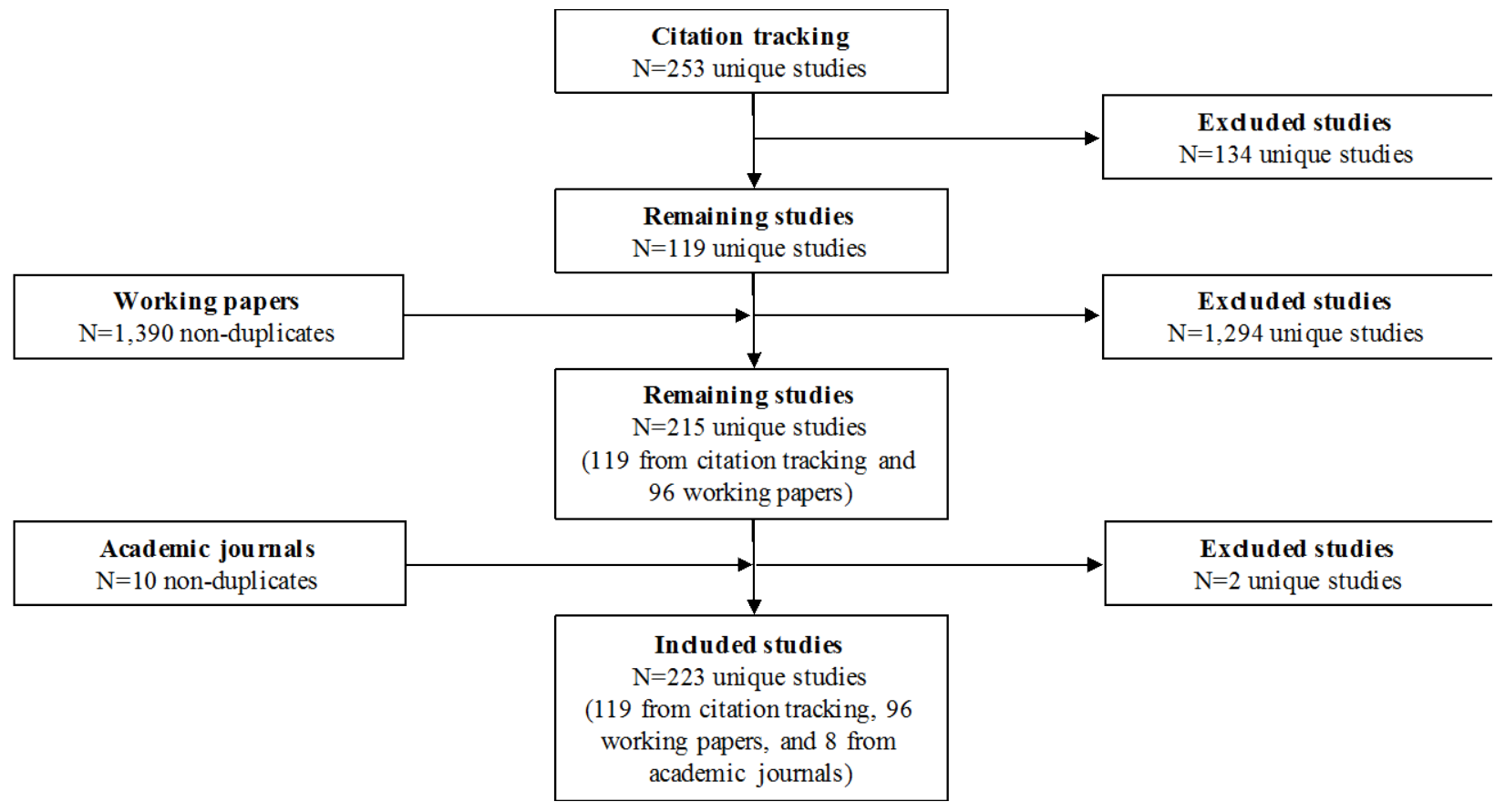

Source: Authors’ construction. 
Figure 2. Classification criteria.

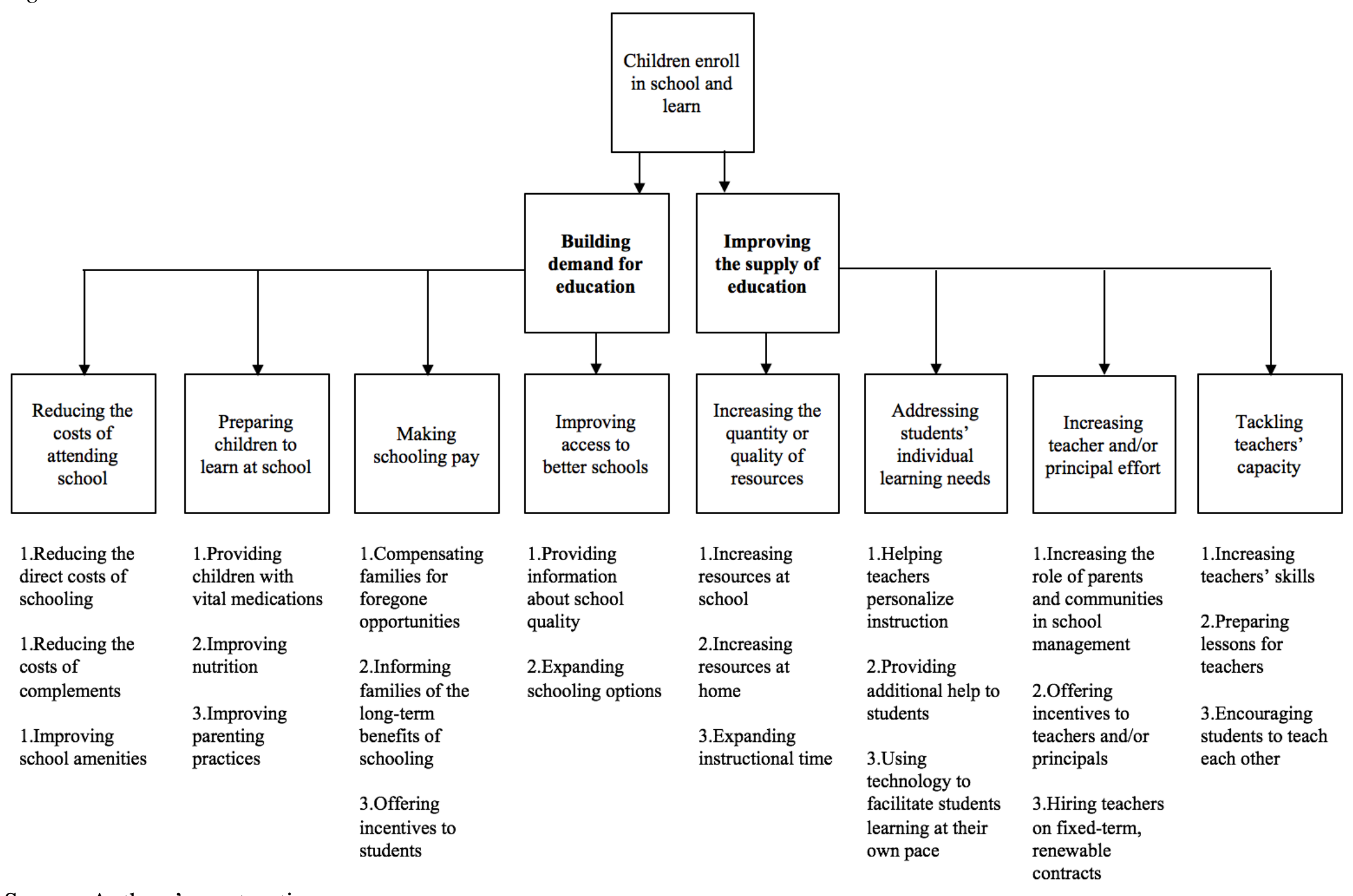

